\title{
A System Dynamics Model Examining Alternative Wildfire Response Policies
}

\author{
Matthew P. Thompson ${ }^{1, *}$, Yu Wei ${ }^{2} \mathbb{C}$, Christopher J. Dunn ${ }^{3}$ and Christopher D. O'Connor ${ }^{4}(\mathbb{D}$ \\ 1 Rocky Mountain Research Station, USDA Forest Service, Fort Collins, CO 80526, USA \\ 2 Warner College of Natural Resources, Colorado State University, Fort Collins, CO 80523, USA; \\ Yu.Wei@colostate.edu \\ 3 College of Forestry, Oregon State University, Corvallis, OR 97331, USA; Chris.Dunn@oregonstate.edu \\ 4 Rocky Mountain Research Station, USDA Forest Service, Missoula, MT 59801, USA; \\ christopher.d.oconnor@usda.gov \\ * Correspondence: matthew.p.thompson@usda.gov; Tel.: +1-970-498-1302
}

Received: 29 April 2019; Accepted: 27 September 2019; Published: 4 October 2019

check for updates

\begin{abstract}
In this paper, we develop a systems dynamics model of a coupled human and natural fire-prone system to evaluate changes in wildfire response policy. A primary motivation is exploring the implications of expanding the pace and scale of using wildfires as a forest restoration tool. We implement a model of a forested system composed of multiple successional classes, each with different structural characteristics and propensities for burning at high severity. We then simulate a range of alternative wildfire response policies, which are defined as the combination of a target burn rate (or inversely, the mean fire return interval) and a predefined transition period to reach the target return interval. We quantify time paths of forest successional stage distributions, burn severity, and ecological departure, and use departure thresholds to calculate how long it would take various policies to restore forest conditions. Furthermore, we explore policy resistance where excessive rates of high burn severity in the policy transition period lead to a reversion to fire exclusion policies. Establishing higher burn rate targets shifted vegetation structural and successional classes towards reference conditions and suggests that it may be possible to expand the application of wildfires as a restoration tool. The results also suggest that managers may be best served by adopting strategies that define aggressive burn rate targets but by implementing policy changes slowly over time.
\end{abstract}

Keywords: forest dynamics; disturbance; modeling; departure; restoration

\section{Introduction}

\subsection{Background and Overview}

In recent years, the fire science and management communities have turned to systems thinking principles to better address the challenges of managing wildfire in an ever-changing and increasingly complex world [1-4]. A key theme is unraveling the "fire paradox", which is essentially a reinforcing feedback loop where the aggressive suppression of wildfires in fire-prone forests leads to an accumulation of hazardous fuels, such that future wildfires burn with higher intensities and resistance to control, ultimately leading to greater demand for suppression [5]. By instead capitalizing on opportunities for expanded use of wildfire as a tool to restore forest conditions and reduce fuel hazards, where ecologically appropriate and allowable, managers can invert feedbacks, wherein wildfire can act as more of a self-regulating mechanism and may even facilitate suppression operations [6-9]. Although preventative removal of vegetation (i.e., mechanical treatment or prescribed burning) to reduce hazardous fuel loads is a more common landscape risk mitigation strategy, myriad constraints 
restrict the scale of implementation, such that treatments may be insufficient to reduced hazard and risk [10-13]. Hence, the interest is in changing responses to wildfires in order to leverage natural fire as a force multiplier for landscape restoration efforts [14].

One barrier to such a change is uncertainty over questions of how frequently and under what conditions wildfire response decisions can deviate from the status quo of aggressive suppression to achieve more desirable fire outcomes. In some fire-prone areas where wildfire has, in recent decades, been managed to return to a more natural role, landscape conditions are now generally more resilient to disturbance [15-17]. In other areas where suppression has persisted, landscape conditions may present greater challenges for reintroducing fire. Expanding rates of burning to reduce the fire deficit is not a risk-free strategy; if the return of fire results in fire severity outside the range of adaptation, then it can serve to further reduce rather than restore landscape resilience [18].

Managers seeking to restore landscapes with wildfire therefore face decisions characterized by complicated tradeoffs and feedbacks that play out over time. Here, we focus on the pace and scale of changes in burning rates as key variables driving the success or failure of wildfire restoration strategies. A comprehensive strategy would necessarily emphasize use of wildland fire (i.e., both planned prescribed fire and unplanned wildfires), and the modeling framework we present is agnostic as to whether burn rate targets are achieved through intentional or unintentional ignitions. To provide one real-world example, on 11 July 2019, the Arapaho and Roosevelt National Forests in Colorado, USA successfully burned 80 ha as part of the planned Red Feather Prescribed Burn project, even as the agency was elsewhere responding to the nearby unplanned Beaver Fire (https://inciweb.nwcg.gov/incident/5027/). Here, we frame our analysis largely around change in wildfire response, given that it is recognized as a major need, opportunity, and a central focus of ongoing planning and decision support efforts [3,6,14].

To evaluate the potential effects of changing wildfire response policies, we rely on modeling and scenario analysis. Other related simulation-based studies have examined various aspects of this problem, including: evaluating the long-term impacts of allowing a single wildfire to burn $[19,20]$, evaluating how the long-term impacts of active forest management vary with burn rates [21], evaluating how varying levels of suppression and fuel treatment over time influence ecological resilience [22], and evaluating near-term feedbacks in fire occurrence and area burned due to allowing lightning-caused wildfires to burn [23]. Notably, Riley et al. [23] found that mean annual landscape burn probability increased by more than an order of magnitude due to a simulated change in wildfire response assuming no suppression actions on natural ignitions. Perhaps most relevant, Collins et al. [24] used a system dynamics model of fire management in Portugal. The authors compared management policies in terms of budgets devoted to suppression versus prevention, finding that emphasizing suppression provides immediate benefits but can cause an increase in fire activity in the long run.

In this paper we propose a dynamic model of a coupled human and natural fire-prone system to evaluate changes in wildfire response policy. The distinguishing features of this study are the emphasis on wildfire response policy, a more thorough exploration of policy alternatives, and the design of dynamic rather than static policy scenarios. Here, a response policy implements particular wildfire restoration practices, defined by specified rates of burning over time, to achieve a targeted mean fire return interval (MFRI; inverse of burn rate) by a targeted attainment time. To isolate the effects of changes in policy on forest and fire dynamics, we treat annual burn rates as deterministic, in effect assuming wildfire response operations can increase burn rates as desired via selective suppression. This modeling framework is based in part on recent advances in preseason planning that pre-identify potential fire control locations that managers can leverage to determine strategic spatial containers within which to manage fire [25-27], as described in more detail below. Note that our modeling framework does not assume that aggressive suppression can stop all wildfires, but rather, explores changes in management that result in more fire on the landscape relative to the status quo of aggressive suppression. In terms of on-the-ground management, this would mean a shift from rapid initial control 
of nearly all ignitions ( $95-98 \%)$ to modified strategies and tactics that enable some ignitions to spread within proactively identified locations under acceptable conditions [28].

The organizing concepts we employ in our modeling effort are forest successional dynamics and, in particular, ecological departure, a key metric in forest restoration planning and landscape risk assessment $[29,30]$. Departure is a measure of how much landscapes have changed from the natural range of variation under reference conditions (i.e., a natural fire regime), measured on the basis of the abundance of different successional classes (S-Classes). Similar to [21], we focus on interactions between S-Class and burn severity, and their behavior over time. Similar to [22,23], we vary landscape burn rates to emulate the effects of alternative wildfire response policies. Similar to [24], we focus on capturing the complex feedback loops and non-linear behavior of wildfires in forested systems, in particular aspects of the fire paradox [31,32].

\subsection{Management Context}

We apply our model to the Southern Rocky Mountain Ponderosa Pine Woodland ecosystem, which we use as a generalized representation of interior western conifer dry forests that account for more than a third of forested area burned in the western USA annually [33]. In these systems, as a result of a century of fire exclusion, forests have degraded ecological integrity and lower resilience to disturbance, and tend to burn at proportionally higher severity than under reference conditions [34]. This system represents ecosystems most affected by fire exclusion and also most likely to benefit from a change in wildfire response policy [35], and hence, is a useful choice for our modeling exercise.

To orient behavior in this system, we present a stylized causal loop diagram that distills the fire paradox into three primary elements: the burn rate, forest density, and burn severity (Figure 1). In this system, as the burn rate decreases (reflective of a fire exclusion management paradigm), forest density increases. As forest density increases, so too does burn severity. Specifically, the percentage of area burned at high severity may increase, even though the overall area burned may be lower due to the decrease in burn rate. As burn severity increases, forest density decreases, which creates a balancing loop. However, as the percentage of high-severity area burned increases, there is increasing sociopolitical pressure to emphasize fire exclusion and further reduce the burn rate to the extent possible. This creates a reinforcing feedback loop via management response, the outcomes of which are reflective of historical fire and forest management policies and the current condition of many dry forests in the western US.

We build from this simplistic model and implement a model of a forested system composed of multiple S-Classes, each with different structural characteristics and propensities for burning at high severity. Our intent is not to recreate the fire paradox per se, as that phenomenon has already been demonstrated elsewhere. Instead, our intent is to explore how to escape from the current "firefighting trap" by exploring policy alternatives and examining the potential consequences (some unintended) of these various policies. To reiterate, we focus on how the pace and scale of changes in landscape burn rate influence forest and fire dynamics. This analysis is similar to, and inspired by, a large body of work in the fuel treatment arena where simulation exercises examine increasing the pace and scale of restoration, often at rates exceeding feasibility, to inform analyses of possible trajectories and associated tradeoffs, along with evaluations of strategic investment alternatives [36-39].

The management context for our analysis is National Forest System lands in the western USA, encompassing the Southern Rocky Mountain Ponderosa Pine woodland ecosystem. A number of factors influence wildfire management in this area: Federal Wildland Fire Management Policy ${ }^{1}$ both allows for and promotes the management of wildfire as a natural process that provides ecosystem benefits [40]; USDA Forest Service Risk Management Protocol requires National Forests to "predetermine the optimal

1 Hereafter when we refer to "policy scenarios" we do not mean changing Federal Policy but rather localized changes in response to wildfires. 
response strategies" based on a risk analysis completed with key stakeholders and partner agencies [41]; and locally-developed Land and Resource Management Plans, along with risk-informed Strategic Response Zones, identify areas and conditions where wildfire response objectives target ecosystem benefit [42]. Following this guidance, in recent years, fire managers have leveraged advanced fire analytics to proactively identify and then execute strategies to restore wildfire to the landscape [43] (Figure 2). Federal land and fire managers across the western USA are engaging in strategic wildfire planning to quantitatively assess and map wildfire risk to resources and assets, pre-identify the safest and most effective fire control opportunities, and develop maps of potential wildfire operational delineations (PODs) that summarize risk by operational opportunities to engage fire [3,42-44]. National Forest Service lands and their partners in Arizona, New Mexico, Washington, and Oregon will be nearing completion of initial strategic wildfire plans by the end of 2019, with efforts ongoing in the remaining western states. Once these plans are in place, they will serve as a foundation for tracking wildfire response actions which are commensurate with the values at risk to facilitate the restoration of wildfire to natural ecosystems when and where appropriate, while also identifying wildfire hazards and suppression opportunities where necessary. Therefore, this context provides a useful opportunity to explore how different wildfire response policies could lead to different future forest ecological conditions, which is an active area of interest for the management of wildfires on public lands in the western USA.

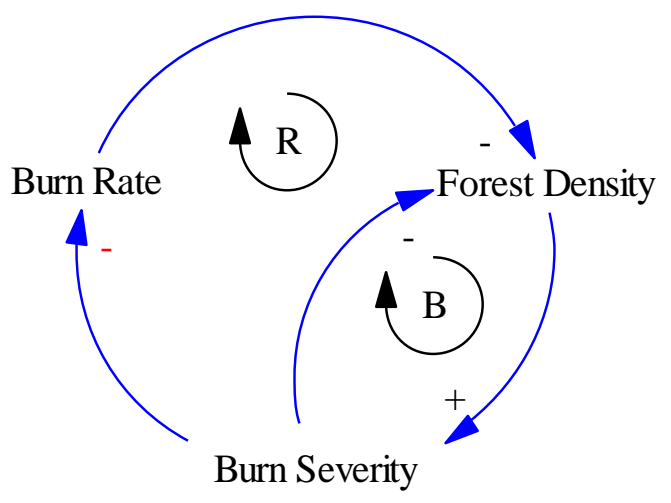

Figure 1. Stylized causal loop diagram of coupled human and natural fire-prone system, highlighting three key drivers of system behavior considered here: forest conditions (density), burn severity, and wildfire response policy (expressed through burn rate). The clockwise arrow with the " $R$ " corresponds to a reinforcing feedback loop, and the clockwise arrow with the " $\mathrm{B}$ " to a balancing feedback loop. Polarity signs indicate the nature of the relationship; for instance, the "-" on the link between burn rate and forest density indicates that as the burn rate increases, forest density decreases. The color of the polarity signs indicates ecological (black) or management (red) effects.

We recognize that the management of wildfires is a more complicated social, ecological, and political issue than can be captured with a single model. To partially address this issue, we incorporate the notion of policy resistance into our scenario analysis to capture the prospect of barriers to effectual change. Policy resistance is a key theme of systems thinking, wherein resistance to change arises because the goals of various actors and subsystems are inconsistent or incompatible [45]. In the case of wildfire, goals to minimize short-term risk to homes and other structures have compromised goals to minimize long-term risk to forested landscapes, a persistent phenomenon that has been characterized as maladaptive [5,46]. Real-world implementation may require more detailed examination into additional issues such as land ownership patterns, fire spread potential and associated risk interdependencies, social context and community characteristics, and system governance [46-48]. Here, we begin our investigation by focusing on the intersection of forest dynamics and wildfire response policies, setting the stage for more complex models considering factors such as active forest management, economic investment theory, and impacts to social and cultural values. We identify possible tradeoffs associated with changing wildfire response, and outline future research directions. 


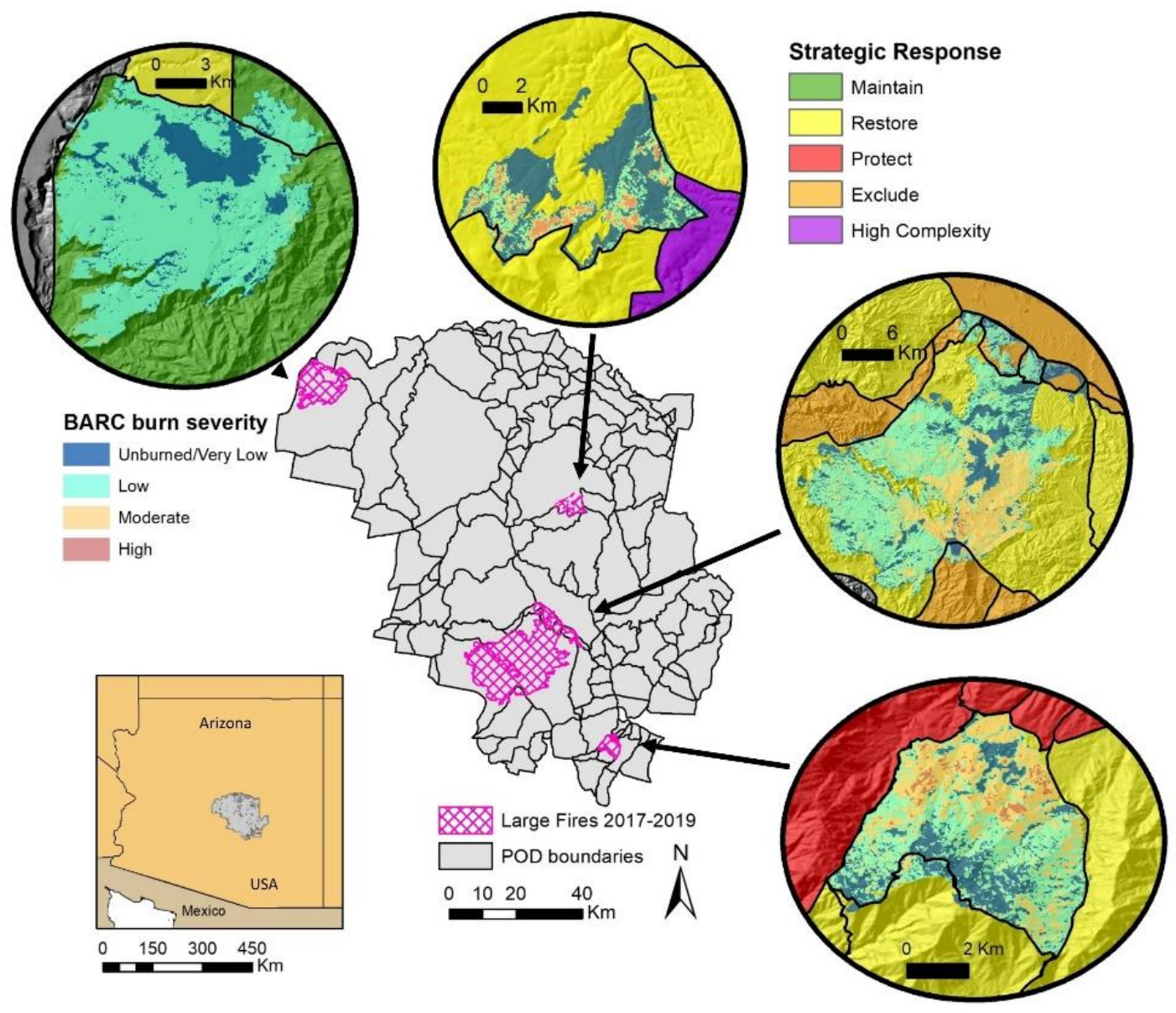

Figure 2. Large wildfires managed in designated "restore" or "maintain" Strategic Response Zones with pre-identified control opportunities on the Tonto National Forest 2017-2019. Fire panels display background strategic wildfire response designation overlaid with Burned Area Reflectance Classification (BARC) initial soil burn severity classes. Clockwise from top, the 2017 Brooklyn Fire burned during monsoon season with no direct containment actions taken; the 2018 Bears Fire also during monsoon season was contained with burn out operations along the southern and eastern POD boundaries; the 2019 Woodbury fire burned during the hotter drier pre-monsoon season and with uncharacteristic herbaceous fuels generated from an extremely wet winter. The fire was contained along POD boundaries to the west and eventually to the north only after breaching the first set of pre-identified potential control opportunities. The 2017 Pinal fire also during the pre-monsoon was actively managed from ignition as a resource benefit fire with a final fire footprint which was nearly identical to the pre-identified POD boundary.

\section{Materials and Methods}

\subsection{Model of Forest and Fire Dynamics}

We built a non-spatial, deterministic system dynamics model of forest and fire dynamics, implemented on a hypothetical 1000 ha landscape. System dynamics models are generally defined by stocks (i.e., levels), flows (i.e., rates of transition in/out of stocks), and feedback loops. In this case, the stocks represent levels of each S-Class, flows represent succession- and disturbance-driven S-Class transitions, and feedback loops emerge from stock-flow relationships following the basic dynamics illustrated in Figure 1 (although more complicated). We implemented the model using the VenSim for Windows Version 7.3.5 software (C) Ventana Systems, Inc., Harvard, MA, USA).

We based our model on a state-and-transition model developed by the LANDFIRE program [49,50] (https://www.landfire.gov/) to simulate long-run dynamics under a natural fire regime. LANDFIRE is 
a multi-partner governmental program that provides geospatial data describing vegetation, wildland fuel, and fire regimes across the United States. Data products provided by LANDFIRE have been used for a wide range of applications, including fire behavior modeling, fuel treatment prioritization, fire planning, and vegetation condition assessment. We were interested in LANDFIRE state-and-transition models of biophysical settings, which simulate the relative amount and transitions between S-Classes due to succession and disturbance. More information on LANDFIRE biophysical setting models, vegetation condition assessment, and departure modeling can be found in $[18,29,30]$ along with (www.landfirereview.org).

Specifically, as described above, we selected the model developed for the "Southern Rocky Mountain Ponderosa Pine Woodland" biophysical setting (ID 10540). This biophysical setting covers large contiguous areas of ponderosa pine in the United States, characterized by low elevation, dry forest conditions with a frequent, low-severity fire regime. There are five primary S-Classes defined for this biophysical setting, which are broken down according to upper layer lifeform, height, and canopy cover (Tables 1 and 2). Natural succession proceeds according to the following flows: $A \rightarrow C ; B \rightarrow E$; $\mathrm{C} \rightarrow \mathrm{D}$. Under reference conditions representative of a natural fire regime, S-Class D dominates the landscape, and tree cover greater than $60 \%$ is considered uncharacteristic (UN). We address transitions into our UN class, as well as their importance, in the following paragraphs.

Table 1. Succession class (S-Class) descriptions for the Southern Rocky Mountain Ponderosa Pine Woodland biophysical setting.

\begin{tabular}{|c|c|c|}
\hline Label & Name & Description \\
\hline A & Early Development-All Structures & $\begin{array}{l}\text { Openings with grass, shrubs, and forbs created after } \\
\text { replacement fire }\end{array}$ \\
\hline B & Mid Development-Closed & $\begin{array}{l}\text { Closed pole-sapling/grass and shrubs, with tree } \\
\text { heights of } 0-10 \mathrm{~m} \text { and forest canopy closure }>30 \%\end{array}$ \\
\hline $\mathrm{C}$ & Mid Development-Open & $\begin{array}{l}\text { Open pole-sapling/grass and shrubs with tree heights } \\
0-10 \mathrm{~m} \text { and forest canopy closure }<30 \%\end{array}$ \\
\hline $\mathrm{D}$ & Late Development-Open & $\begin{array}{l}\text { Open large trees/grass and shrubs with tree heights > } \\
10 \mathrm{~m} \text { and canopy cover between } 30-60 \%\end{array}$ \\
\hline $\mathrm{E}$ & Late Development-Closed & $\begin{array}{l}\text { Closed large trees, poles, saplings, and shrubs with } \\
\text { tree heights }>10 \mathrm{~m} \text { and forest canopy cover between } \\
30-60 \%\end{array}$ \\
\hline UN-B & Mid Development_-Uncharacteristic & $\begin{array}{l}\text { Uncharacteristic closed mid-development with forest } \\
\text { canopy cover }>60 \%\end{array}$ \\
\hline UN-E & Late Development-Uncharacteristic & $\begin{array}{l}\text { Uncharacteristic closed late-development with forest } \\
\text { canopy cover }>60 \%\end{array}$ \\
\hline
\end{tabular}

Table 2. Succession class (S-Class) mapping rules for the Southern Rocky Mountain Ponderosa Pine Woodland biophysical setting. S-Class labels can be cross-referenced with S-Class names and descriptions provided in Table 1.

\begin{tabular}{|c|c|c|c|c|c|c|c|c|c|c|c|}
\hline \multirow{2}{*}{$\begin{array}{l}\text { Upper Layer } \\
\text { Lifeform }\end{array}$} & \multirow{2}{*}{$\begin{array}{l}\text { Height } \\
\text { (m) }\end{array}$} & \multicolumn{10}{|c|}{ Canopy Cover } \\
\hline & & $0-10$ & $11-20$ & $21-30$ & $31-40$ & $41-50$ & $51-60$ & $61-70$ & $71-80$ & $81-90$ & 91-100 \\
\hline Herb & $0-0.5$ & A & A & A & A & $\mathrm{A}$ & A & $\mathrm{A}$ & $\mathrm{A}$ & $\mathrm{A}$ & $\mathrm{A}$ \\
\hline Herb & $0.5-1.0$ & A & A & A & A & A & A & A & A & A & A \\
\hline Herb & $>1.0$ & A & A & A & A & $\mathrm{A}$ & $\mathrm{A}$ & $\mathrm{A}$ & $\mathrm{A}$ & A & $\mathrm{A}$ \\
\hline Shrub & $0-0.5$ & A & A & A & $\mathrm{A}$ & $\mathrm{A}$ & A & $\mathrm{A}$ & $\mathrm{A}$ & A & $\mathrm{A}$ \\
\hline Shrub & $0.5-1.0$ & A & A & A & A & A & A & A & A & A & A \\
\hline Shrub & $1.0-3.0$ & A & A & A & A & $\mathrm{A}$ & A & A & A & A & $\mathrm{A}$ \\
\hline Shrub & $>3.0$ & A & A & A & A & $\mathrm{A}$ & A & A & A & A & A \\
\hline Tree & $0-5$ & $\mathrm{C}$ & $\mathrm{C}$ & $\mathrm{C}$ & B & B & B & UNB & UNB & UNB & UNB \\
\hline Tree & $5-10$ & $\mathrm{C}$ & $\mathrm{C}$ & $\mathrm{C}$ & B & B & B & UNB & UNB & UNB & UNB \\
\hline Tree & $10-25$ & $\mathrm{D}$ & D & $\mathrm{D}$ & E & E & E & UNE & UNE & UNE & UNE \\
\hline Tree & $25-50$ & $\mathrm{D}$ & $\mathrm{D}$ & $\mathrm{D}$ & E & E & E & UNE & UNE & UNE & UNE \\
\hline Tree & $>50$ & $\mathrm{D}$ & $\mathrm{D}$ & $\mathrm{D}$ & E & E & E & UNE & UNE & UNE & UNE \\
\hline
\end{tabular}


The LANDFIRE model was developed to model system behavior under pre-suppression-era reference conditions, meaning it does not capture the accumulation of UN fuels due to fire exclusion. We therefore opted to add UN succession flows resulting from the accumulation of fuels due to fire suppression. These UN flows would occur contemporaneously with natural succession (NS) flows, but would instead add to stocks with denser forest conditions (i.e., $\mathrm{A} \rightarrow \mathrm{B} ; \mathrm{C} \rightarrow \mathrm{B} ; \mathrm{D} \rightarrow \mathrm{E}$ ). Further, we opted to add a fuel accumulation multiplier for each S-Class to account for the rapid densification of forest and accumulation of fuels due to growth of understory (e.g., grass and shrubs), in addition to smaller diameter and shade-tolerant trees beneath the forest canopy. We mean rapid in a relative sense, in that the UN fuel accumulation may lead to changes in S-Class which are faster than natural succession transition times (see Figures 1 and 4 in [35]).

Our model expanded the LANDFIRE state-and-transition model by considering the proportion of the 1000 ha landscape at any point in time that would be in one of multiple S-Classes. That is, instead of modeling S-Classes as state variables that may change in each time period, our model considers the dynamic behavior of stocks of S-Classes and the flows between them. In the original model, state transitions are due to probabilistic disturbances and deterministic (time-dependent) natural succession. We instead model flows between stocks with continuous rates, described below. The drawback is the loss of probabilistic variation, but the gains from changing to a stock-and-flow model are the abilities to evaluate the dynamics of distribution of S-Classes over time, and to capture nonlinear behavior emerging from interactions of succession and management.

In particular we were interested in fire-driven transitions, which are a function of burn severity. Whereas the state-and-transition model used specific burn rates for each S-Class state and burn severity combination, we were interested in applying a common burn rate to the entire landscape. In terms of model workflow, this means the exogenous (policy-driven) burn rate determines the total area of the landscape burned each year, while the endogenous distribution of S-Class stocks determined by forest and disturbance dynamics in turn determines the relative percentages of area burned at low, moderate, and high severity. To accomplish this, we simply derived conditional burn severity probabilities from the LANDFIRE model parameters (see Table 3, described later).

Our modeling framework is designed as follows. First, we define the following parameters:

$i \in$ index for S-Class $i$

$\mathbb{T}_{i} \quad$ natural succession transition time (i.e., measured by years) for S-Class $i$

$B R_{i}$ burn rate (i.e., annual burn rate) for S-Class $i$

$f a_{i}$ user-defined fuel accumulation rate parameter for S-Class $i$. By setting $f a_{i} \geq 1$, we would assume the S-Class $i$ transfers into the corresponding $U N$ class faster than the natural succession rate calculated as $\left(\frac{1}{T_{i}}\right)$

Note that for our simulations, we kept the burn rate and fuel accumulation parameter constant across S-Classes, but retained generality for the formulation in case S-Class specific burn rates were defined later. Next, we defined equations for the uncharacteristic succession (UN) and natural succession (NS) flow rates:

$$
\begin{gathered}
U N_{i}=\min \left(\frac{1}{T_{i}}, f a_{i}\left(\frac{1}{T_{i}}\right)\left(1-B R_{i}\right)^{T_{i}}\right) \\
N S_{i}=\left(\frac{1}{T_{i}}\right)-U N_{i}
\end{gathered}
$$

In the baseline LANDFIRE model, UN flows are not modeled, which is equivalent to setting flow rate $U N_{i}$ to zero, and the NS flow rate $N S_{i}$ is the inverse of the natural succession transition time (i.e., a transition time of 50 years corresponds to an annual flow rate of 1/50). The logic behind calculating flow rate $U N_{i}$ is based on the probability of the S-Class $i$ not experiencing fire $\left(1-B R_{i}\right)$ over the duration of that transition time (hence the multiplication of this probability for $T_{i}$ years). As the burn rate decreases, this compound probability increases, putting a larger proportion of the total stock 
outflow into the UN flow. Because the fuel accumulation parameter $\left(f a_{i}\right)$ could be set to greater than one, UN flows could exceed the value of $\left(1 / T_{i}\right)$, hence, the min operand in Equation (1).

Table 3. Summary of all S-Class flows. For completeness we list the entire model even if some rows could be condensed (e.g., low and moderate severity fire both maintain $\mathrm{C}$ as $\mathrm{C}$ ).

\begin{tabular}{|c|c|c|c|c|}
\hline From S-Class & To S-Class & Flow Type & Flow Rate Determinants & Flow Rate \\
\hline A & A & Low-Severity Fire & Conditional Probability & $B R_{A} \times 1.00$ \\
\hline A & B & Alternative Succession & - & 0.01 \\
\hline A & B & UN & $T_{A}=50$ & Equation (1) \\
\hline A & $\mathrm{C}$ & NS & $T_{A}=50$ & Equation (2) \\
\hline $\mathrm{B}$ & $\mathrm{A}$ & High-Severity Fire & Conditional Probability & $B R_{B} * 0.21$ \\
\hline B & B & Low-Severity Fire & Conditional Probability & $B R_{B} * 0.11$ \\
\hline B & $\mathrm{C}$ & Moderate-Severity Fire & Conditional Probability & $B R_{B} * 0.68$ \\
\hline $\mathrm{B}$ & $\mathrm{D}$ & Alternative Succession & - & 0.03 \\
\hline $\mathrm{B}$ & $\mathrm{E}$ & NS & $T_{B}=70$ & Equation (2) \\
\hline B & UNB & UN & $T_{B}=70$ & Equation (1) \\
\hline $\mathrm{C}$ & $\mathrm{A}$ & High-Severity Fire & Conditional Probability & $B R_{C} * 0.03$ \\
\hline $\mathrm{C}$ & B & UN & $T_{C}=70$ & Equation (1) \\
\hline $\mathrm{C}$ & $\mathrm{C}$ & Low-Severity Fire & Conditional Probability & $B R_{C} * 0.88$ \\
\hline $\mathrm{C}$ & $\mathrm{C}$ & Moderate-Severity Fire & Conditional Probability & $B R_{C} * 0.09$ \\
\hline $\mathrm{C}$ & $\mathrm{D}$ & NS & $T_{C}=70$ & Equation (2) \\
\hline $\mathrm{D}$ & A & High-Severity Fire & Conditional Probability & $B R_{D} * 0.02$ \\
\hline $\mathrm{D}$ & $\mathrm{D}$ & Low-Severity Fire & Conditional Probability & $B R_{D} * 0.89$ \\
\hline $\mathrm{D}$ & $\mathrm{D}$ & Moderate-Severity Fire & Conditional Probability & $B R_{D} * 0.09$ \\
\hline $\mathrm{D}$ & $\mathrm{E}$ & Alternative Succession & - & 0.001 \\
\hline $\mathrm{D}$ & E & UN & $T_{D}=50$ & Equation (1) \\
\hline $\mathrm{E}$ & A & High-Severity Fire & Conditional Probability & $B R_{E} * 0.25$ \\
\hline $\mathrm{E}$ & $\mathrm{D}$ & Moderate-Severity Fire & Conditional Probability & $B R_{E} * 0.50$ \\
\hline $\mathrm{E}$ & $\mathrm{D}$ & Insect/Disease & - & 0.02 \\
\hline $\mathrm{E}$ & $\mathrm{E}$ & Low-Severity Fire & Conditional Probability & $B R_{E} * 0.25$ \\
\hline $\mathrm{E}$ & UNE & $\mathrm{UN}$ & $T_{E}=50$ & Equation (1) \\
\hline UNB & A & High-Severity Fire & Conditional Probability & $B R_{U N B} * 0.35$ \\
\hline UNB & B & Moderate-Severity Fire & Conditional Probability & $B R_{U N B} * 0.60$ \\
\hline UNB & UNB & Low-Severity Fire & Conditional Probability & $B R_{U N B} * 0.05$ \\
\hline UNB & UNE & NS & $T_{U N B}=70$ & Equation (2) \\
\hline UNE & $\mathrm{A}$ & High-Severity Fire & Conditional Probability & $B R_{U N E} * 0.40$ \\
\hline UNE & $\mathrm{E}$ & Moderate-Severity Fire & Conditional Probability & $B R_{U N E} * 0.45$ \\
\hline UNE & UNE & Low-Severity Fire & Conditional Probability & $B R_{U N E} * 0.15$ \\
\hline
\end{tabular}

In addition to UN flows, we also explored adding two UN stocks as new S-Classes, corresponding to the lower right portion of Table 2. Specifically, we added (UNB), similar to B but with canopy cover > $60 \%$, and (UNE), similar to E but with canopy cover $>60 \%$. The new UN flows into these new S-Classes are $\mathrm{B} \rightarrow \mathrm{UNB}$ and $\mathrm{E} \rightarrow \mathrm{UNE}$, which are similarly calculated according to Equations (1) and (2). In a preliminary analysis, we developed five model formulations that varied according to whether UN flows were included, whether UN stocks were included, and whether the fuel accumulation parameter was set to 1.0 or 2.0. Appendix A contains more detailed results on comparative analysis of alternative model formulations. We ultimately opted to use the model with both UN stocks and UN flows, and a fuel accumulation parameter of 2.0 (UNS-fa-2; see Appendix A); the results for all policy and scenario analysis correspond to this model formulation.

The dynamics underlying all of the succession- and disturbance-driven flows used in our model are depicted in Figure 3 and summarized with more detail in Table 3. The figure also illustrates the role of the burn rate and fire response policy variables, which, for simplicity, we only show for S-Class C. The connections between Figure 3 and the stylized causal loop diagram in Figure 1, which stem directly from the underlying model structure, can be explained as follows. First, as the burn rate decreases, the UN flow rates increase, shifting the S-Class distribution towards denser stocks. The net effect for 
S-Class C would be relatively lower NS flow rates into S-Class D (open forest) and higher UN flow rates into S-Class B (closed forest). This shift to denser forest stocks in turn results in comparatively higher conditional rates of high-severity fire (e.g., 0.21 for S-Class B versus 0.02 for S-Class D; Table 3), which eventually lead to greater rates of transition into S-Class A. With a lower burn rate, S-Class A then has relatively higher flow rates into S-Class B (UN flow) instead of back into S-Class C (NS flow), which further sets the landscape on a trajectory of denser forests with higher conditional rates of high fire severity. Further, as we explore in policy resistance scenarios (described below), increased rates of high-severity fire and corresponding increases in S-Class A can lead to policy responses which are geared towards fire exclusion, creating a reinforcing loop.

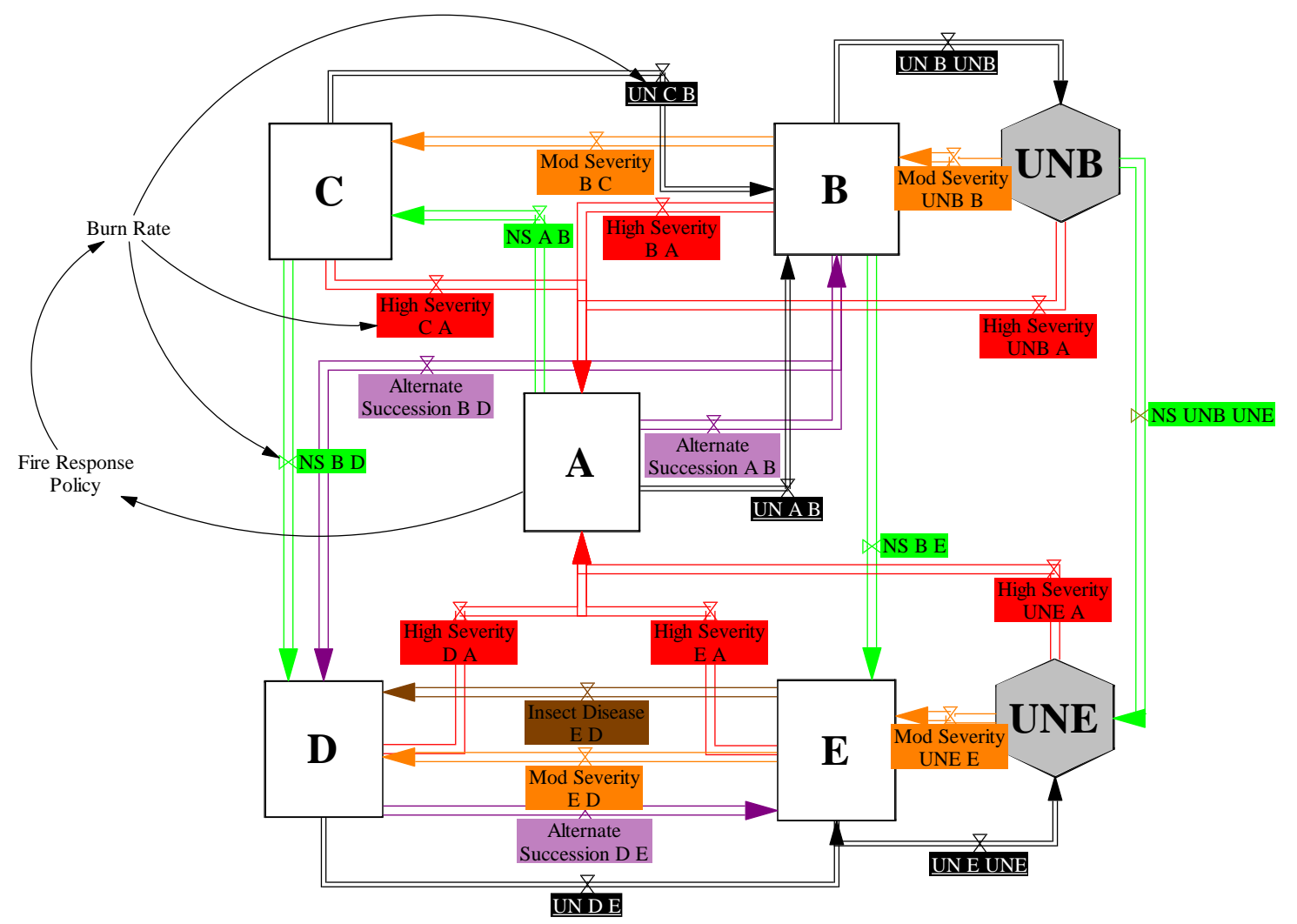

Figure 3. Simplified diagram of the stock-and-flow model. Square boxes represent the standard S-Class stocks in the original LANDFIRE model (A-E), and the grey hexagons represent the added unnatural S-Class stocks (UNB and UNE). Flows are labeled by type and the corresponding "from to" stocks, and the types are color coded as follows: NS (green), UN (black), high-severity fire (red), moderate severity fire (orange), alternate succession (purple), and insect/disease (brown). For example, “NS A B" represents a natural succession flow from S-Class A to S-Class B. An auxiliary Burn Rate variable, determined by the Fire Response Policy, acts on UN/NS flows as well as fire-related flows. Here for simplicity, we only display relationships between the Burn Rate and S-Class C. The amount of S-Class A influences the Fire Response Policy, as described later.

We made no changes to preexisting LANDFIRE transition times or non-fire disturbance rates. Further, we did not adjust any LANDFIRE pathways labeled as "alternative succession," which reflect underlying forest dynamics that may result in transitions distinct from NS pathways (i.e., these are considered separate from our UN flows). As described in the Appendix A, we did estimate new conditional burn severity probabilities for fire-related flow rates for the new UN stocks. The D, E, and UNE stocks have no NS flows, although D and E both have UN flows into denser stocks (E and UNE, respectively). The UNE stock can only be reduced through burning at moderate and high-severity fire. In all cases, low-severity fire maintains the stock, and sometimes moderate severity fire does as well. 
Within the model, fire that maintains the S-Class is not directly modeled as a flow that changes stock levels, but we track these to account for fire severity over time.

The area burned at high severity is jointly determined by the burn rate, S-Class distribution, and S-Class conditional fire severity probabilities. The lower bound is a landscape composed entirely of S-Class A, which for any burn rate would result in 0 ha of high-severity fire. The upper bound results from a landscape composed entirely of S-Class UNE, which for a burn rate of 0.1 (100 ha out of 1000 ha burned) would result in 40 ha burned. The spectrum of S-Class distributions in between these two extremes dictates the actual amount of area burned at high-severity fire in any simulation year.

\subsection{Wildfire Response Policy Scenarios}

We initially designed a total of seven wildfire response policy scenarios, which include a status quo (SQ) policy along with six alternative policies (Table 4). For simulation purposes, all policies begin from steady state conditions (2000-year simulation, 10-year MFRI, 0.1 burn rate), and are simulated over a 250-year time horizon. Specifically, we simulate 50 years of a natural fire regime (10-year MFRI, 0.1 burn rate) then 100 years of fire exclusion (80-year MFRI, 0.0125 burn rate) before initiating changes in response policy. All response policies are implemented for a duration of 100 years. The exception is the Status Quo (SQ) policy of fire exclusion (80-year MFRI), which is implemented consistently over a 200-year time horizon after the 50 years of the natural fire regime. The alternative response policies are defined by two key variables, i.e., target mean fire return interval (MFRI) and target attainment time, which correspond to the scale and pace of the restoration strategy. The labeling schema for these alternative policies is: "Target MFRI-Target Attainment Time." We designed these strategies to cover a range of managerial preferences, ranging from what we colloquially label "Hot and Fast" (10-10) to "Cool and Slow" (40-40), with a spectrum of combinations in between. The complete set of policies we evaluated is: 10-10, 10-40, 20-20, 30-30, 40-10, and 40-40.

Table 4. Summary of wildfire response policies. We label each policy by a pair of numbers: the first number is the targeted mean fire return interval (MFRI); the second number is a predefined transition period to reach the targeted MFRI.

\begin{tabular}{cccc}
\hline Policy Label & Policy Description & $\begin{array}{c}\text { Target Mean Fire } \\
\text { Return Interval (Years) }\end{array}$ & $\begin{array}{c}\text { Target Attainment Time } \\
\text { (Years) }\end{array}$ \\
\hline SQ & Status Quo & 80 & 1 \\
$10-10$ & Hot and Fast & 10 & 10 \\
$10-40$ & Hot and Slow & 10 & 40 \\
$20-20$ & Partially Hot and Fast & 20 & 20 \\
$30-30$ & Partially Cool and Slow & 30 & 30 \\
$40-10$ & Cool and Fast & 40 & 10 \\
$40-40$ & Cool and Slow & 40 & 40 \\
\hline
\end{tabular}

We evaluated policy performance in terms of departure from steady state conditions, amount of high-severity fire, and time to restore $\mathrm{D}$ and $\mathrm{E}$. For the former, we calculated mean values of total departure as well as the UNE stock as indicators of degraded forest conditions (UNB stocks, while also an indicator of degraded conditions, are generally very low due to low initial levels of B). For simplicity we calculate departure as the absolute deviation of current S-Class area from initial reference conditions, summed over all S-Classes. We also kept track of whether individual S-Class status would be considered surplus, similar, or deficit, where the surplus (deficit) threshold is defined as being greater than $+33 \%$ from reference conditions (less than $-33 \%$ ). For severity, we reported both percentage and area burned at high severity. We define "time to restore" as the time at which S-Class stocks are returned to similar status; for $\mathrm{D}$, this is a return from deficit, and for $\mathrm{E}$, this is a return from surplus.

Lastly, we evaluated the potential for policy resistance, wherein unintended or undesirable consequences from changing fire policy could induce pressures that inhibit change (Table 5). We used 
the presence of a surplus of A (a proxy for excessive high-severity fire) as a trigger to initiate policy resistance, and considered two policy resistance scenarios: "CS," which reverts to the "Cool and Slow" policy of 40-40, and "SQ," which reverts to the SQ fire exclusion policy (i.e., 80-1). The response policy (i.e., the burn rate, or equivalently the MFRI) reverts to the original policy anytime A is no longer in surplus. Only response policies 10-10 and 10-40 triggered policy resistance.

Table 5. Summary of policy resistance scenarios. We label each policy by a pair of numbers: the first number is the targeted mean fire return interval (MFRI); the second number is a predefined transition period to reach the targeted MFRI. Parenthetical values define the target under the policy resistance scenario.

\begin{tabular}{cccc}
\hline Policy Label & Policy Description & $\begin{array}{c}\text { Target Mean Fire } \\
\text { Return Interval (Years) }\end{array}$ & $\begin{array}{c}\text { Target Attainment Time } \\
\text { (Years) }\end{array}$ \\
\hline $10-10-\mathrm{CS}$ & Hot and Fast, then Cool and Slow & $10(40)$ & $10(40)$ \\
$10-10-S Q$ & Hot and Fast, then Status Quo & $10(80)$ & $10(1)$ \\
$10-40-\mathrm{CS}$ & Hot and Slow, then Cool and Slow & $10(40)$ & $40(40)$ \\
$10-40-S Q$ & Hot and Slow, then Status Quo & $10(80)$ & $40(1)$ \\
\hline
\end{tabular}

\section{Results}

\subsection{Policy Analysis}

First, we present the results for the seven wildfire response policies over 100 years of implementation (after 50 years of the natural fire regime and 100 years of the fire exclusion regime). Table 6 presents summary metrics regarding restoration time, departure, and high-severity fire. As would be expected, the status quo (SQ) policy continues a trajectory of forest degradation during the 100-year policy implementation period, with the highest mean departure, mean area of UNE stock, and mean percentage of high-severity fire by area. However, because of the low overall burn rate under the SQ policy, the mean area burned at high severity remains comparatively low. In general, as the target burn rate decreases (longer MFRI), time to restore, departure, and percent high-severity fire all increase. The policies with a 10-year targeted MFRI are the only ones able to restore both D (from deficit) and E (from surplus) within the 100-year policy implementation period, and furthermore, yield the lowest mean departure, lowest mean UNE stock, and the lowest mean percent high severity. The 10-10 policy has the highest mean area burned at high severity during the 100-year policy implementation period due to the highest overall burn rate and the fastest target attainment time. The 10-40 policy has a lower mean area burned at high severity than the 10-10 policy because of the lower burn rates in the 40-year transition period to reach the targeted 10-year MFRI. For all other policies, the time to restore $\mathrm{E}$ is greater than 100 years, and in all cases, the time to reduce $\mathrm{E}$ from the surplus is longer than the time to increase D from deficit. In other words, the effect of fire exclusion is to increase the stocks of $\mathrm{E}$ and UNE so much that implementation of higher burning rates may be insufficient to deplete uncharacteristic stock levels and restore forest conditions within the 100-year policy implementation period. This points to the role for active forest management to accelerate restoration and set the stage for more aggressive burning, a point we will return to in the Discussion section.

At the end of the 250-year simulation horizon, the distribution of S-Classes reflects the influence of the various wildfire response policies (Figure 4). Perhaps most notable is the difference between the simulated steady state (SS) after 2000 years with a 10-year return interval (see description of SS in Appendix A), in the leftmost column, and the SQ policy in the next column. The results generally confirm patterns evident from Table 6, for example, the high degree of departure exhibited by the SQ policy (969 ha). The SQ policy has the highest levels of closed and uncharacteristic S-Classes (B, E, UNB, and UNE), and the lowest levels of open S-Classes (C and D). Total departure for the 10-10 policy at year 250 is reduced to 89 ha, whereas total departure for the $40-40$ policy remains relatively high at 535 ha. 
Table 6. Summary metrics across wildfire response policies simulated over a 100-year time horizon (after 50 years of a natural fire regime and 100 years of a fire exclusion regime). SQ = Status Quo. The labeling schema for the other policies is: "Target MFRI-Target Attainment Time".

\begin{tabular}{ccccccc}
\hline $\begin{array}{c}\text { Fire } \\
\text { Management } \\
\text { Policy }\end{array}$ & $\begin{array}{c}\text { Time to } \\
\text { Restore } \mathbf{D} \\
\text { (Years) }\end{array}$ & $\begin{array}{c}\text { Time to } \\
\text { Restore E } \\
\text { (Years) }\end{array}$ & $\begin{array}{c}\text { Mean } \\
\text { Departure } \\
\text { (ha) }\end{array}$ & $\begin{array}{c}\text { Mean UNE } \\
\text { (ha) }\end{array}$ & $\begin{array}{c}\text { Mean Percent } \\
\text { High Severity } \\
\text { Fire }\end{array}$ & $\begin{array}{c}\text { Mean } \\
\text { High-Severity } \\
\text { Fire (ha) }\end{array}$ \\
\hline SQ & n/a & n/a & 954.54 & 153.93 & 15.62 & 1.95 \\
$10-10$ & 12 & 52 & 270.41 & 19.67 & 4.36 & 3.68 \\
$10-40$ & 20 & 69 & 328.75 & 32.18 & 5.60 & 3.45 \\
$20-20$ & 22 & $>100$ & 381.36 & 39.14 & 6.85 & 2.87 \\
$30-30$ & 36 & $>100$ & 567.42 & 65.94 & 9.53 & 2.71 \\
$40-10$ & 46 & $>100$ & 650.16 & 79.15 & 10.78 & 2.59 \\
$40-40$ & 64 & $>100$ & 715.80 & 94.35 & 11.77 & 2.57 \\
\hline
\end{tabular}

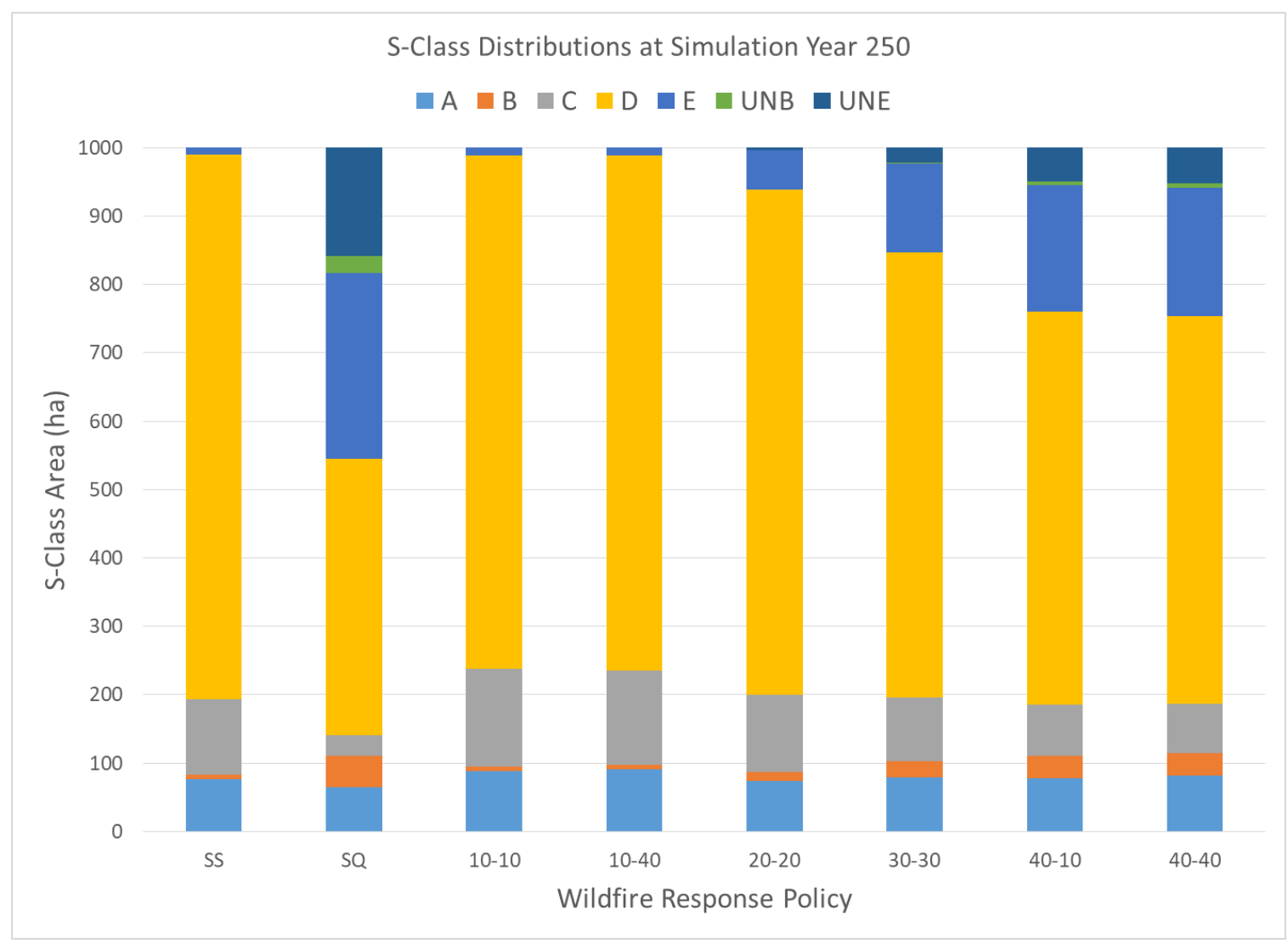

Figure 4. Distribution of area in each S-Class (ha) on the hypothetical 1000 ha landscape, as it varies with fire management policy. All S-Classes are as defined in Tables 1 and 2. SS = steady state solution after 2000 years of a simulated natural fire regime., and all other wildfire response policies are defined as in Table 4.

Patterns of fire severity over time differ depending on whether the variable of interest is total area burned at high severity or percentage of area burned at high severity. Figures 5 and 6 present behavior over time graphs for these two variables, respectively, for two contrasting wildfire response policies: "Hot and Fast" (10-10) and "Cool and Slow" (40-40). In these and subsequent figures, behaviors across policies are identical through year 150, representing the common natural and exclusion fire regimes. In Figure 5, the initiation of fire exclusion at year 50 results in a steep decline in area burned at high severity, although the effect of fuel accumulation and forest densification gradually increases the area of high-severity fire between year 50 and year 150. At year 150 with the implementation of the 10-10 policy, the area of high-severity fire sharply increases, due to increased rates of burning in denser forest conditions prone to high-severity fire. After the target burn rate is reached after 10 years of policy 
transition, the 10-10 policy has a steep decline of area burned at high-severity fire, as the stocks more prone to burning with high severity (B, E, UNB, and UNE) are more rapidly depleted. The patterns seen in Figure 6 regarding percentage of area burned at high severity are effectively the opposite of those in Figure 5. Specifically, high-severity percentage under the 40-40 policy declines at a slower rate, and sustains a higher overall level, throughout the 100 years of policy implementation. However, less area is burned under the 40-40 policy, which leaves overall forest conditions with higher departure (Table 6).

Lastly, we present behavior over time graphs of S-Class A, D, and E stock levels, across the seven wildfire response policies (Figures 7-9). Figure 7 illustrates the potential unintended consequences of attempting relatively rapid restoration through increased rates of burning, which can result in uncharacteristic recruitment into A because of excessively high rates of high-severity fire. Figures 8 and 9 help visualize the time paths restoring $\mathrm{D}$ and $\mathrm{E}$ stocks (Table 6), and furthermore highlight the tradeoffs across time to restore and amount of high-severity fire. The 10-10 policy, which is the fastest to restore $\mathrm{D}$ and $\mathrm{E}$, also results in a surplus of $\mathrm{A}$ that persists for 46 years (the 10-40 policy results in a surplus that persists for 37 years). The SQ policy only further depletes (increases) the D (E) stock, although stock levels begin to asymptote, resulting in a landscape largely comprised of D, E, and UNE stocks (Figure 4).

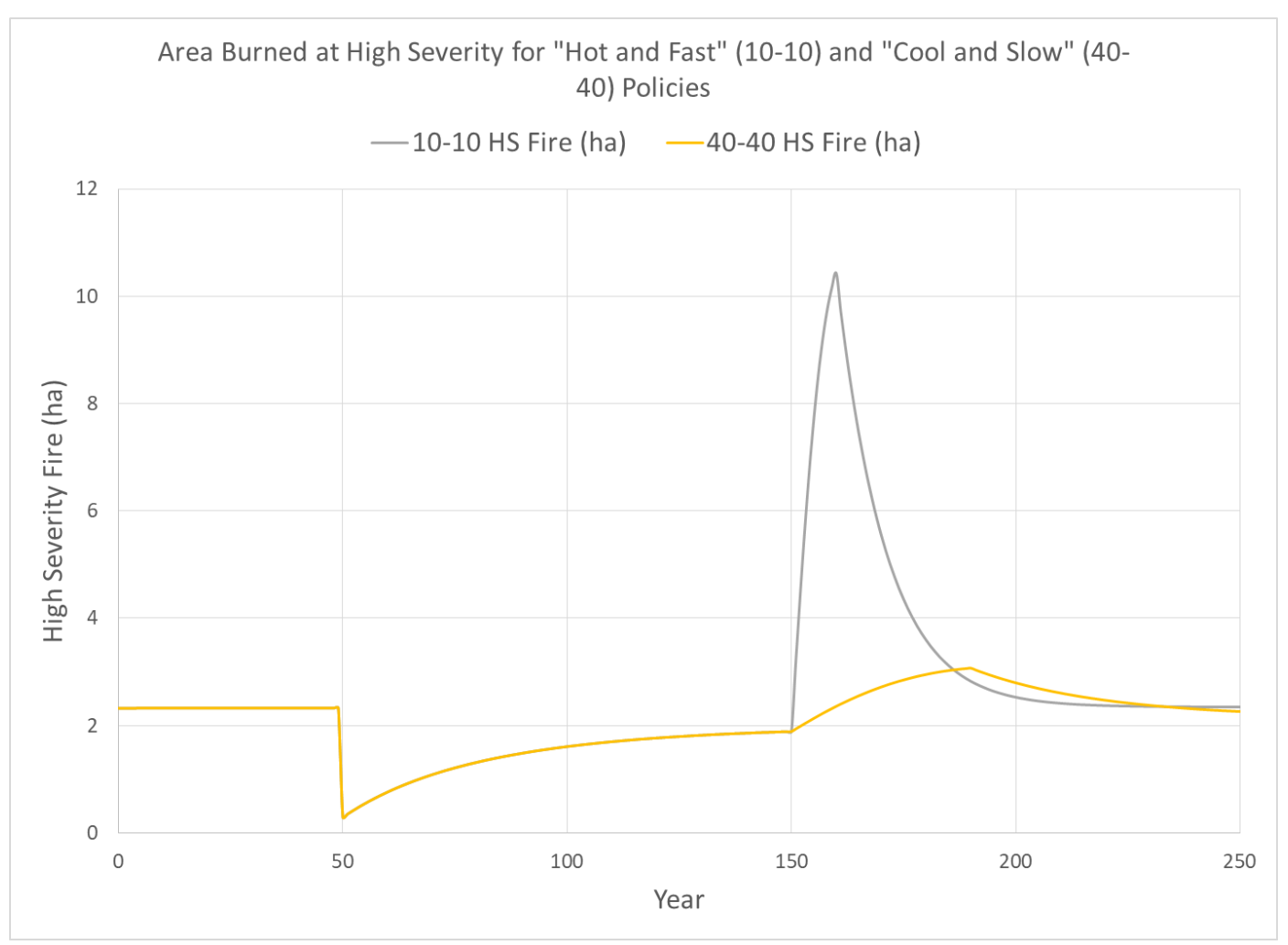

Figure 5. Behavior over time graph of high-severity fire area burned, for the 10-10 and 40-40 policies. Starting from year 150, alternative fire management policies are implemented and compared. High-severity fire area burned peaks sharply with the 10-10 policy, and then rapidly depletes to reach nearly equivalent levels to the $40-40$ policy. 


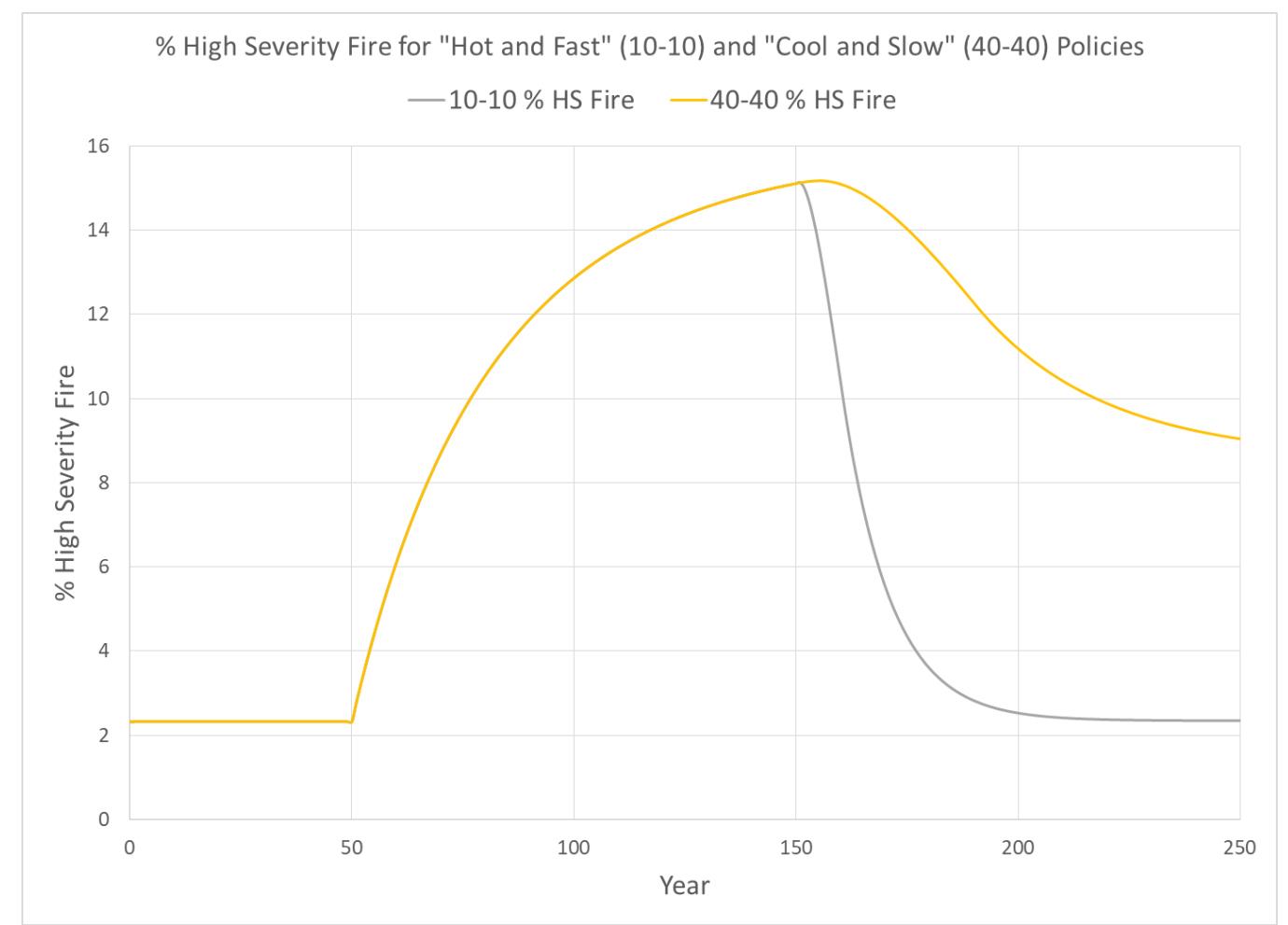

Figure 6. Behavior over time graph of high-severity fire percentage, for the 10-10 and 40-40 policies. Starting from year 150, alternative fire management policies are implemented and compared. High-severity fire percentage drops less steeply and persists for longer with the 40-40 policy.

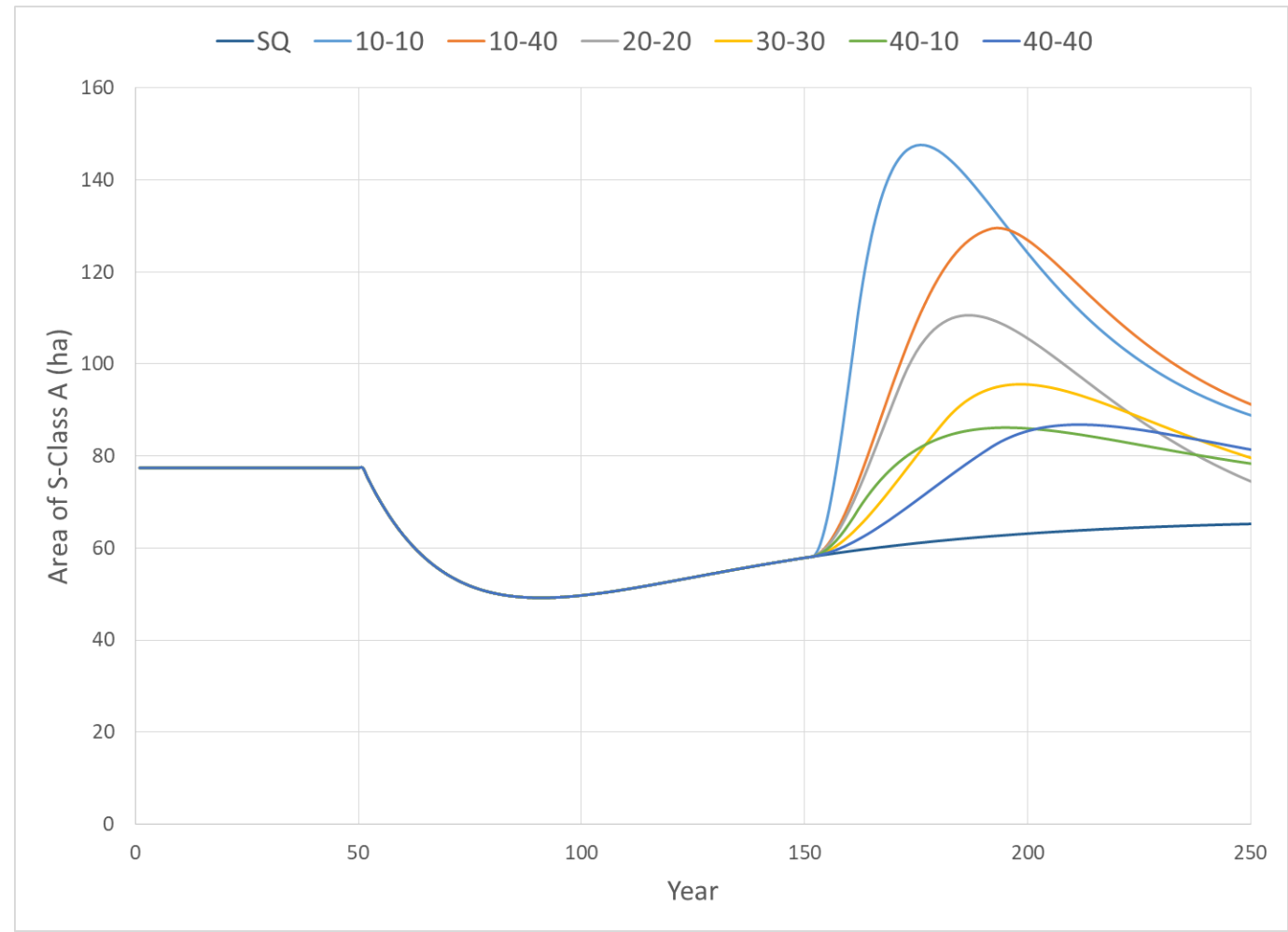

Figure 7. Behavior over time graph of S-Class A levels, for seven wildfire response policies in Table 4. Starting from year 150, alternative policies are implemented. The higher burn rates increase the stock levels of S-Class A, in some cases to surplus status due to high rates of high-severity fire in other S-Classes. 


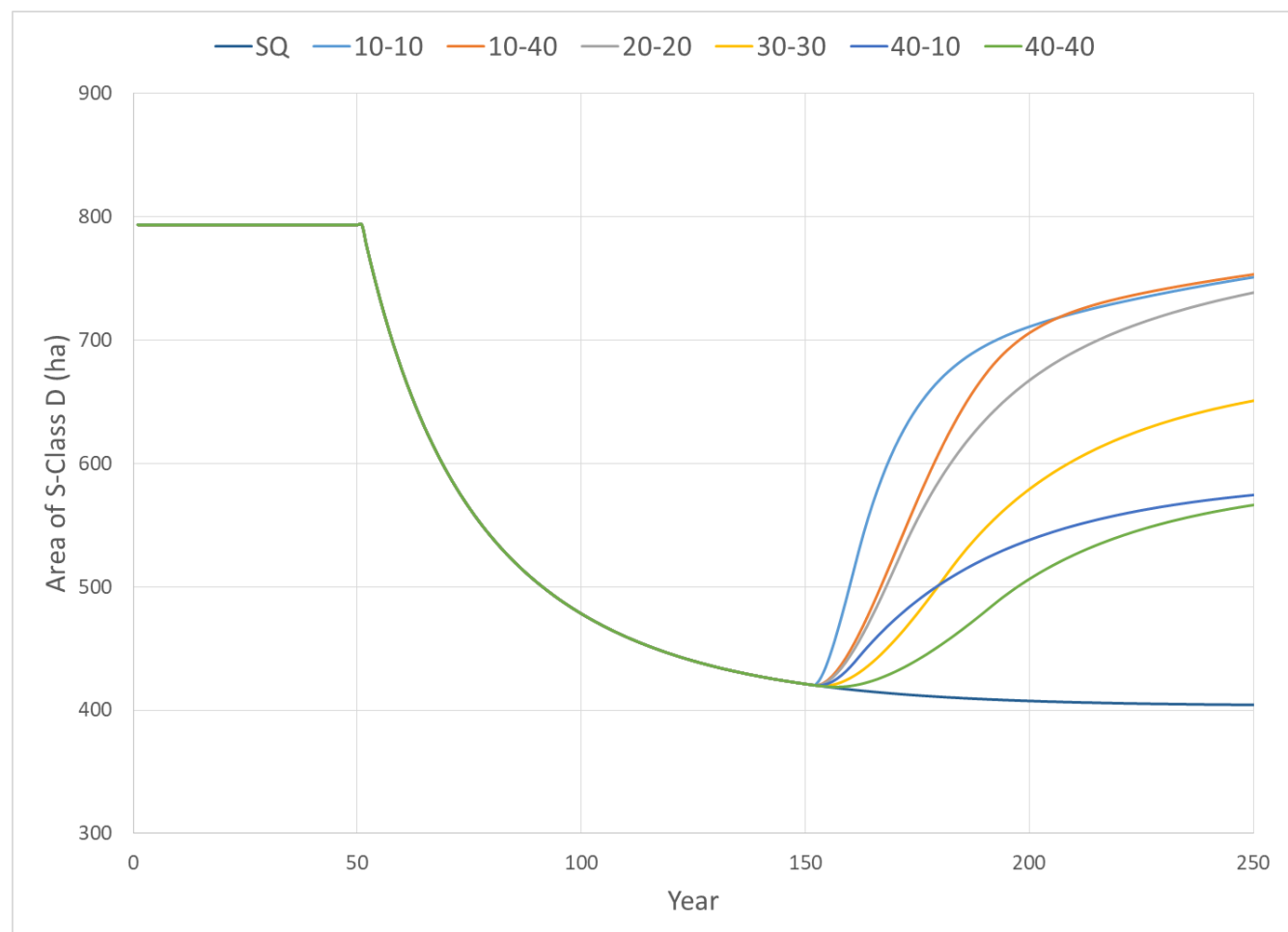

Figure 8. Behavior over time graph of S-Class D levels, for seven wildfire response policies in Table 4. Starting from year 150, alternative policies are implemented. The higher rates of burning increase (restore) stocks of S-Class D.

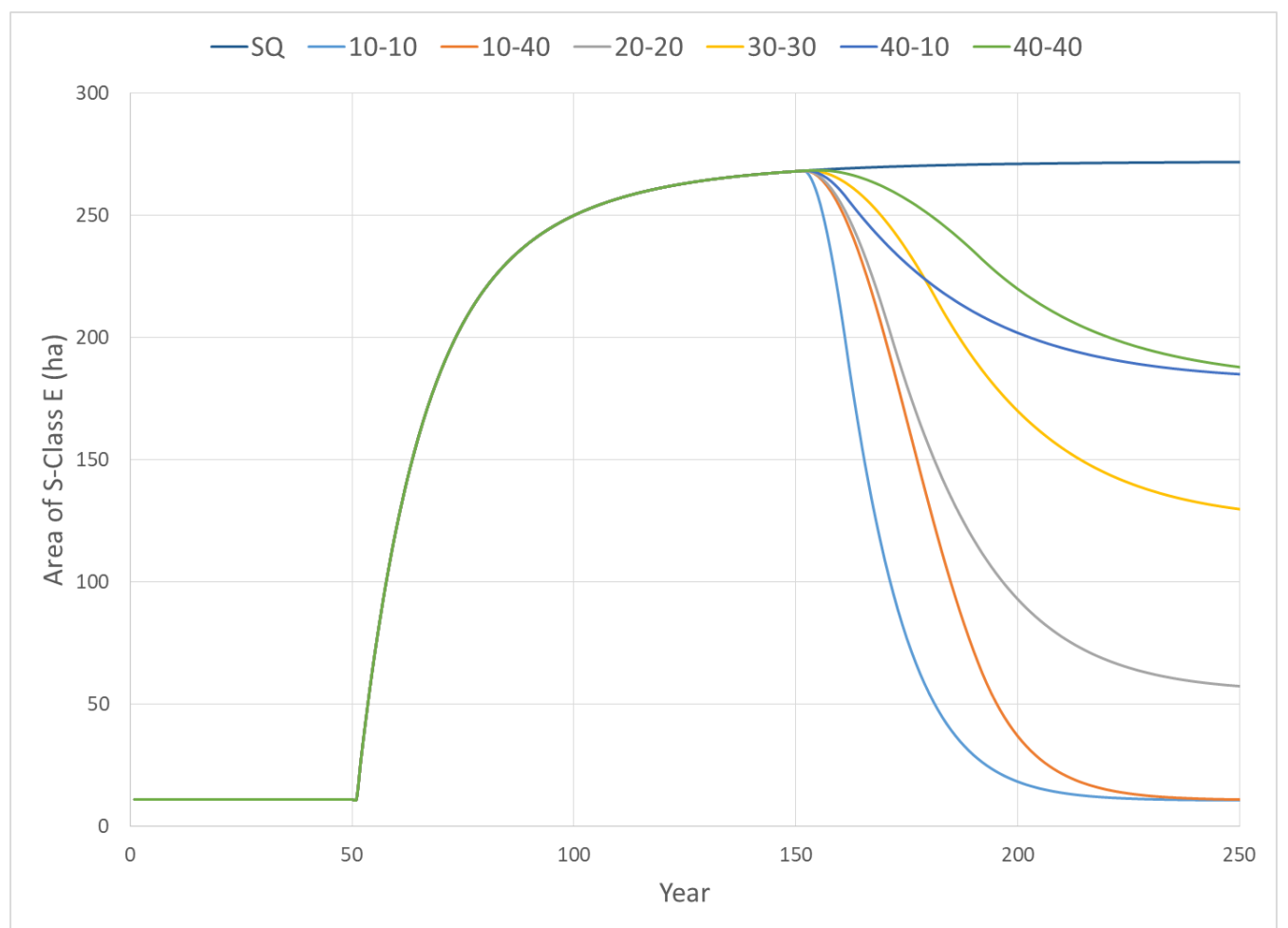

Figure 9. Behavior over time graph of S-Class E levels, for seven wildfire response policies in Table 4. Starting from year 150, alternative fire management policies are implemented. The higher rates of burning decrease (restore) stocks of S-Class E. 


\subsection{Policy Resistance}

Introducing policy resistance has the effect of delaying restoration attainment time, increasing departure, and increasing percent of high-severity fire (Table 7). Due to oscillatory behavior (see Figure 10), we do not report the first time that D/E stocks are restored, but rather, the first time that the restoration is sustained. This effect of dampening policy effectiveness is especially evident for the resistance scenarios that revert to the SQ policy. Where the possibility exists for this resistance scenario to be realized, the results indicate that increasing the target attainment time (i.e., slowing down the rate of restoration, or reducing the slope of the burn rate) may yield better results. The 10-40-CS policy resistance scenario generally performs the best among those compared in Table 7 , and is similar to the 20-20 policy displayed in Table 6 .

Table 7. Summary metrics across wildfire response policies along with policy resistance scenarios. The trigger for policy resistance is a surplus of A, indicative of excessively or undesirably high rates. This table presents the same set of summary metrics as Table 6, but limited to the four policy resistance scenarios listed in Table 5.

\begin{tabular}{ccccccc}
\hline $\begin{array}{c}\text { Fire Management } \\
\text { Policy and Resistance } \\
\text { Scenario }\end{array}$ & $\begin{array}{c}\text { Time to } \\
\text { Restore D } \\
\text { (Years) }\end{array}$ & $\begin{array}{c}\text { Time to } \\
\text { Restore E } \\
\text { (Years) }\end{array}$ & $\begin{array}{c}\text { Mean } \\
\text { Departure } \\
\text { (ha) }\end{array}$ & $\begin{array}{c}\text { Mean UNE } \\
\text { (ha) }\end{array}$ & $\begin{array}{c}\text { Mean Percent } \\
\text { High-Severity } \\
\text { Fire }\end{array}$ & $\begin{array}{c}\text { Mean } \\
\text { High-Severity } \\
\text { Fire (ha) }\end{array}$ \\
\hline 10-10-CS & 12 & $>100$ & 428.20 & 35.09 & 6.71 & 3.78 \\
10-10-SQ & 48 & $>100$ & 580.85 & 51.36 & 8.77 \\
10-40-CS & 20 & 97 & 396.58 & 37.13 & 6.53 & 3.83 \\
10-40-SQ & 20 & $>100$ & 517.35 & 46.57 & 3.54 \\
\hline
\end{tabular}

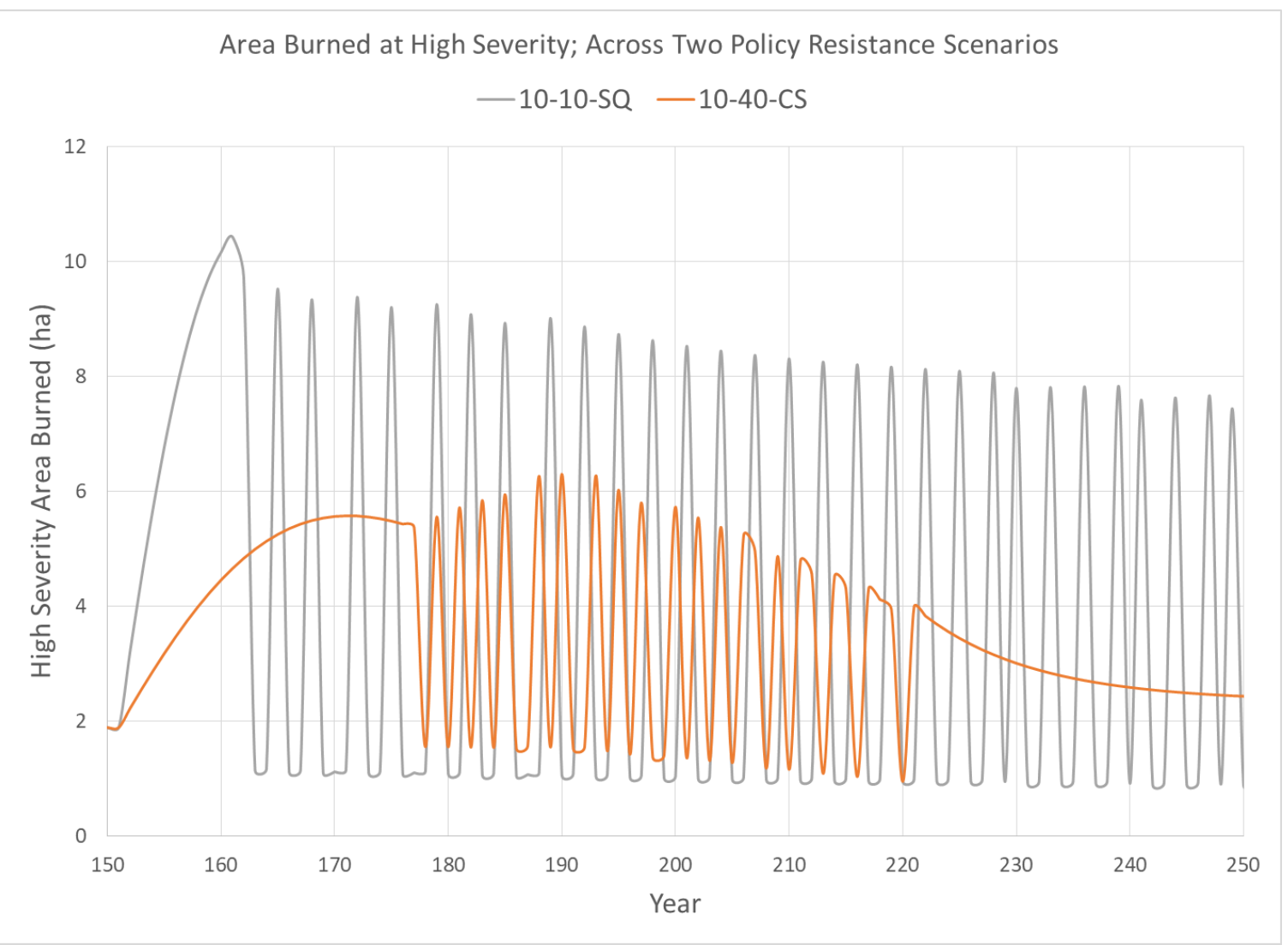

Figure 10. Behavior over time graph of high-severity area burned levels, for two policy resistance scenarios (10-10-SQ and 10-40-CS). The x-axis is shortened to display only years 150-250 (i.e., the years over which the policy resistance scenario is active), to better compare behavior over this time period. The 10-10-SQ policy results in more oscillations, over a longer duration, with higher swings in high-severity area burned. 
As alluded to above, oscillatory behavior emerges as policy resistance is triggered and reverted (i.e., as stocks of $\mathrm{A}$ go in and out of surplus status). Figure 10 displays the behavior of a high-severity area burned for the two most divergent policy resistance scenarios: 10-10-SQ and 10-40-CS. Policy resistance activates earlier and persists longer for the 10-10-SQ scenario. The higher amplitude of the swings associated with 10-10-SQ reflect the higher burning rates and corresponding higher area burned at high severity (which recruits into a surplus of A). The 10-40-CS policy eventually reaches a point where there is no further generation of a surplus of $\mathrm{A}$, so the resistance is not triggered and high-severity area burned continues to decline. Referring back to Figure 5, the difference between the behavior of the high-severity area burned under the 10-10 and the 10-10-SQ scenarios is dramatic. In the 10-10 scenario without resistance, the initial pulse of the high-severity area burned quickly depletes the denser forested stocks and a steady state of low area burned at high severity persists over time. The initiation of policy resistance means that pulses of a relatively high amount of the high-severity area burned could persist for a century or more. This may imply the importance of predicting and analyzing the long-term influence of a fire response policy. Once a policy is selected, there would be advantages of consistently implementing it to achieve the long-term goals.

\section{Discussion}

\subsection{Policy Insights and Management Recommendations}

Policy analysis results demonstrate that there are potentially significant tradeoffs across policy options. Such tradeoffs are not readily apparent from looking at summary metrics in Table 1 and Figure 4, but rather from examining the respective trajectories of each policy over time (Figures 5-9). Namely, the "cooler" and "slower" strategies (i.e., those with lower burn rates and longer attainment times) burn less area at high severity and avoid recruitment of surplus S-Class A, but with slower declines of denser stocks (especially $\mathrm{E}$ and UNE) and slower restoration of D from deficit status. Conversely the "Hot and Fast" 10-10 policy is most effective at restoring D, but also generates the highest amount of high-severity fire and surpluses of S-Class A when moving towards the historical reference conditions.

The possible unintended consequences of more aggressive policies do not continue indefinitely; the 10-10 policy ultimately reaches a state with the lowest total departure, but could be problematic in the short term during the policy transition phase. The introduction of policy resistance in effect extended the policy transition phase, extended the time to restore S-Class stocks, and generated pulses of high-severity fire that persisted across the simulation time horizon. The more aggressive policy resistance scenarios, which inhibited restoration the most, unfortunately might also be the most reflective of real-world policy resistance in some fire-prone areas. As an example, county commissioners in southwestern Oregon, USA recently penned a letter requesting that federal land management agencies pursue full suppression of all wildfires. And yet, even with aggressive resistance, establishing higher burn rate targets did move the landscape towards reference conditions and suggested that it may be possible to escape the "fire paradox." The results therefore suggest opportunities for the expanded application of wildfire as a forest restoration tool.

Of the policies we analyzed, it seems the target burn rate has a greater overall influence on S-Class dynamics than the target attainment time. For a given attainment time, increasing the burn rate led to faster and more comprehensive restoration of S-Class stocks (e.g., 10-10 versus 40-10). For a given burn rate, increasing the attainment time dampened recruitment into surplus A and generated less policy resistance (e.g., 10-10 versus 10-40). This suggests managers may be best served by adopting "hot and slow" strategies that define aggressive burn rate targets but by implementing that policy change slowly over time.

Perhaps the most notable finding is that only the most aggressive policies restore S-Class E by the end of the 100-year time horizon. For all other policies, and for aggressive policies with policy resistance, the surplus of E never goes away. This reflects the enduring legacy of fire exclusion, where 
uncharacteristically dense forest conditions may persist for decades or longer, hence the need for active forest management to accompany changes in burn policy, another point that we address in the following section.

\subsection{Limitations and Extensions}

The stylized model presented here was intentionally developed to be parsimonious, and is clearly a simplification of a much more complicated social-ecological system. Simulated system behaviors that align with real-world observations include increasing forest degradation, as measured by departure, and an increased percentage of high-severity fire due to fire exclusion. However, the use of a consistent burn rate overlooks natural variation in the annual area burned and assumes a greater degree of control over fire dynamics than may actually exist, especially where increased fire severity may be correlated with increased resistance to control [51]. Perhaps equally important, our model formulation doesn't allow for feedbacks from fire exclusion and fuel accumulation that increase the area burned [24], which would tend to increase both the percentage and the total area burned at high severity. This points to extensions that account for stochasticity and resistance to control along with management policy in jointly determining the annual area burned. Future work will focus specifically on capturing interannual variability in the area burned though Monte Carlo simulation, and on presenting statistical results with confidence intervals rather than deterministic point estimates. A further extension would be to add a variable for the patch size of area burned at high severity, which could serve as another indicator of forest degradation [52] as well as an indicator of resistance to control and firefighter safety in future fire seasons $[53,54]$.

Another obvious extension is to adopt spatially-explicit dynamic modeling frameworks e.g., $[55,56]$. Here we opted to focus on long-term dynamics associated with management policies, and abstracted away from some of the spatial complexity. At certain scales of analysis, however, these spatial dependencies may be less as important to capture, opening the door for management applicability of our model. For instance, it could be possible to apply such system dynamics modeling to individual management units to inform development of long-term management strategies. Each model could be parameterized to account for unit-level conditions, and could be indexed with additional variables such as proximity to at-risk assets, fire escape potential, patch size distributions, etc. This could tie directly to the PODs concept introduced earlier, where fire management units on National Forest System lands in the western United States are being associated with broad wildfire response strategies based on near-term assessment of risks, some of which promote more fire on the landscape based on assessment of forest S-Class distributions [42,43,57]. System dynamics modeling of these units could augment these strategies by providing a longer-term perspective on the consequences of implementing alternative rates of burning and other management interventions.

Adding a spatial dimension to the modeling framework would also open doors to more credible model active forest management and the application of controlled burning. Reducing the stocks of dense forest conditions through proactive forest management is a primary risk mitigation strategy employed on forested landscapes in many regions, and can be particularly important where increasing the rate of burning would lead to undesirable fire severity, given current forest conditions (as explored through the policy resistance scenarios). A straightforward extension would be to account for the role of active forest management by allowing management-driven transitions in S-Class stocks, targeting the denser stocks (e.g., B, E, UNB, UNE; Table 2). These transitions would in effect be the opposite of existing fuel accumulation flows, resulting in transitions from closed to open stocks. In this case, an expanded policy matrix would include policy variables related to the pace and scale of forest management, in addition to the pace and scale of burning from wildfire. Incorporating spatial information such as adjacency of similar S-Classes in need of treatment could help with the identification of feasibly-sized treatment units or burn blocks. Further, incorporating relative management costs would allow for analysis of options from an investment theory perspective and, ideally, inform the design of efficient combinations of management interventions. 
There are other options for expanding the set of policy alternatives as well. A range of hybrid strategies could be pursued, including targeting burn rates by S-Class and changing the slopes of these burn rates over time, both with more nuance around how departure influences burn rate. Targeting specific S-Classes could be a proxy for the increased application of controlled burning outside of the main fire season, and conditional severity probability distributions could even be updated to reflect less extreme conditions. As another example, rather than looking only at the surplus of A to trigger a policy change, the model could evaluate how changes in the burn rate would lead to increases in surplus or deficit across multiple S-Classes, and could balance those impacts within a more integrated assessment framework [30]. It would then be possible to design optimal burn rate policies based on a weighted objective function.

Lastly, on the topic of objectives, our modeling framework focused on ecological objectives related to forest condition, but did not address broader socioeconomic objectives that may be just as important drivers of forest and fire management. Notably, potential damages to communities and water supply infrastructure, along with the public health impacts of smoke, are important variables to consider. These variables could influence policy resistance (e.g., higher resistance to increased burn rates near communities), and avoided damages could be brought into the policy analysis framework to help determine return-on-investment. Another dynamic element to bring into the model could be how climate change may exacerbate burn severity and hinder regeneration $[22,58]$. The compound effects of this would certainly highlight the importance of minimizing high-severity fire, especially as continued burning further entrenches a state change that may be undesirable.

\section{Conclusions}

We developed a system dynamics model of wildfire in a forested system. With this model, we were able to replicate observed system behavior and further illustrated the possible consequences of changing wildfire response policy to use fire as a forest restoration tool. A key finding is that pursuing aggressive burn rate targets, but implementing policy change slowly over time, may restore forest conditions without undesirable rates of burn severity and departure in the interim. With future work, we aim to expand this model to examine a broader decision space, including active forest management and community protection, and to better capture spatial and probabilistic aspects.

Author Contributions: Conceptualization, M.P.T., Y.W., and C.J.D.; Methodology, M.P.T., Y.W., and C.J.D.; Software, M.P.T.; Formal Analysis, M.P.T.; Writing-Original Draft Preparation, M.P.T.; Writing-Review \& Editing, M.P.T., Y.W., C.J.D., and C.D.O.; Project Administration, M.P.T.

Funding: This research received no external funding.

Acknowledgments: Alex Masarie contributed to development of preliminary models, and Don Helmbrecht provided guidance on LANDFIRE data and analysis. Mary Lata provided BARC mapping products for the Tonto National Forest. Two anonymous reviewers provided useful and constructive feedback.

Conflicts of Interest: The authors declare no conflict of interest.

\section{Appendix A}

In total we compared five model formulations: (1) Baseline, based on the original LANDFIRE state-and-transition model, which includes only natural succession (NS) pathways; (2) UNF-fa-1, a modified model including uncharacteristic flows (UNF) and a fuel accumulation (fa) rate parameter of 1; (3) UNF-fa-2, similar to (2) but with a fuel accumulation rate parameter of 2; (4) UNS-fa-1, which expands the UNF models to include uncharacteristic stocks (UNS) with a fuel accumulation rate parameter of 1; and (5) UNS-fa-2, similar to (4) but with a fuel accumulation rate parameter of 2.

First, we describe the impact of adding UN flows and the role of the fuel accumulation rate parameter. Figure A1 demonstrates how annual flow rates change with the landscape burn rate and the user-defined fuel accumulation rate parameter, for an S-Class with an example of 50-year natural transition time. In the absence of UN flows, the flow rate would be insensitive to burn rate, at a constant value of 0.02 . The addition of the UN flows instead has NS flows dominating at the natural 
burn rate of 0.1 (MFRI of 10 years), switching to majority UN flow when the burn rate exceeds 0.014 (MFRI exceeds 70 years). When the fuel accumulation rate parameter increases to 2, the shift to NS flows is more rapid as the MFRI increases (burn rate decreases).

Next, we describe adding UN stocks as new S-Classes. It was necessary to estimate conditional burn severity probability distributions for these new S-Classes; our assumed values for these are presented in Figure A2. We based these estimates on the existing distributions for B and E, in both cases reducing low and moderate severity fire in order to increase the probability of high-severity fire.

We compared model formulations in terms of steady state behavior for high-severity fire percentage and area of S-Class D across a range of annual burn rates (corresponding to MFRIs of 10, 15, 20, 30, $40,50,60,70,80,90$, and 100 years). Steady state values are derived from simulating 2000 years of forest and fire dynamics, with initial conditions seeded from steady state conditions derived from the Baseline formulation. We did not consider these constant alternative burn rates as management policies, but rather wanted to see how the various models behaved under different rates of burning. Specifically, we were interested in seeing the degree to which they captured observed increases in uncharacteristic fuel loads due to fire exclusion. Figure A3 presents results of the steady state analysis illustrating the influence of annual burn rate on high-severity fire percentage. Figure A4 similarly contrasts steady state results for the same five modeling formulations but instead displays the steady state area of S-Class D, used here as an indicator of overall forest health. A useful way to interpret Figures A3 and A4 is to go from right to left along the $\mathrm{x}$-axis, moving from the assumed burn rate of a natural fire regime (0.1, or equivalently a 10-year MFRI) towards lower burn rates achieved through fire exclusion policies.

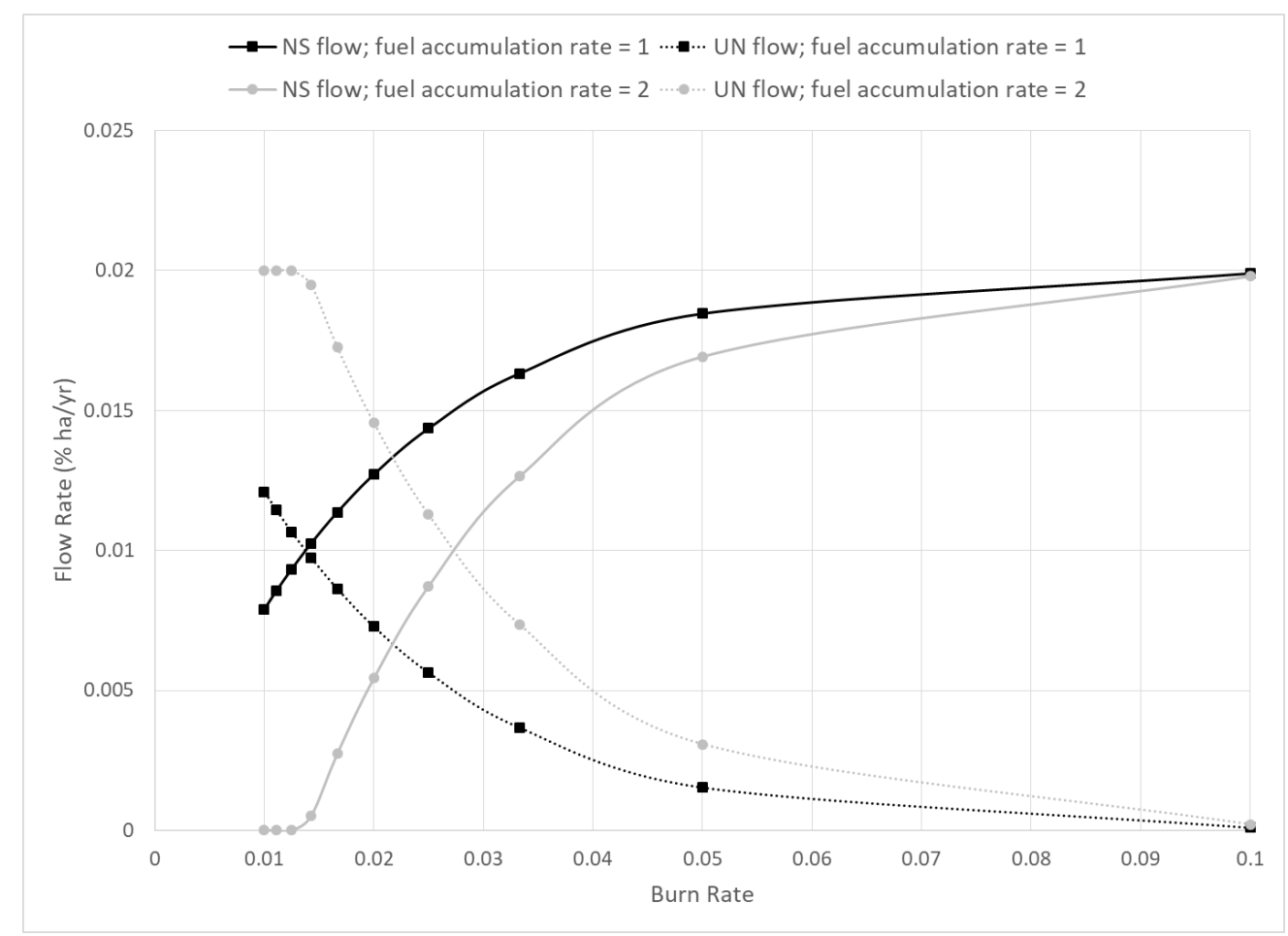

Figure A1. Illustration of influence of annual burn rate (x-axis) and fuel accumulation parameter (fa) on the flow rates for uncharacteristic (UN) and natural succession (NS). Note that identical line colors and symbols indicate the same fuel accumulation rates, with solid and dashed lines representing NS and UN flows, respectively. 


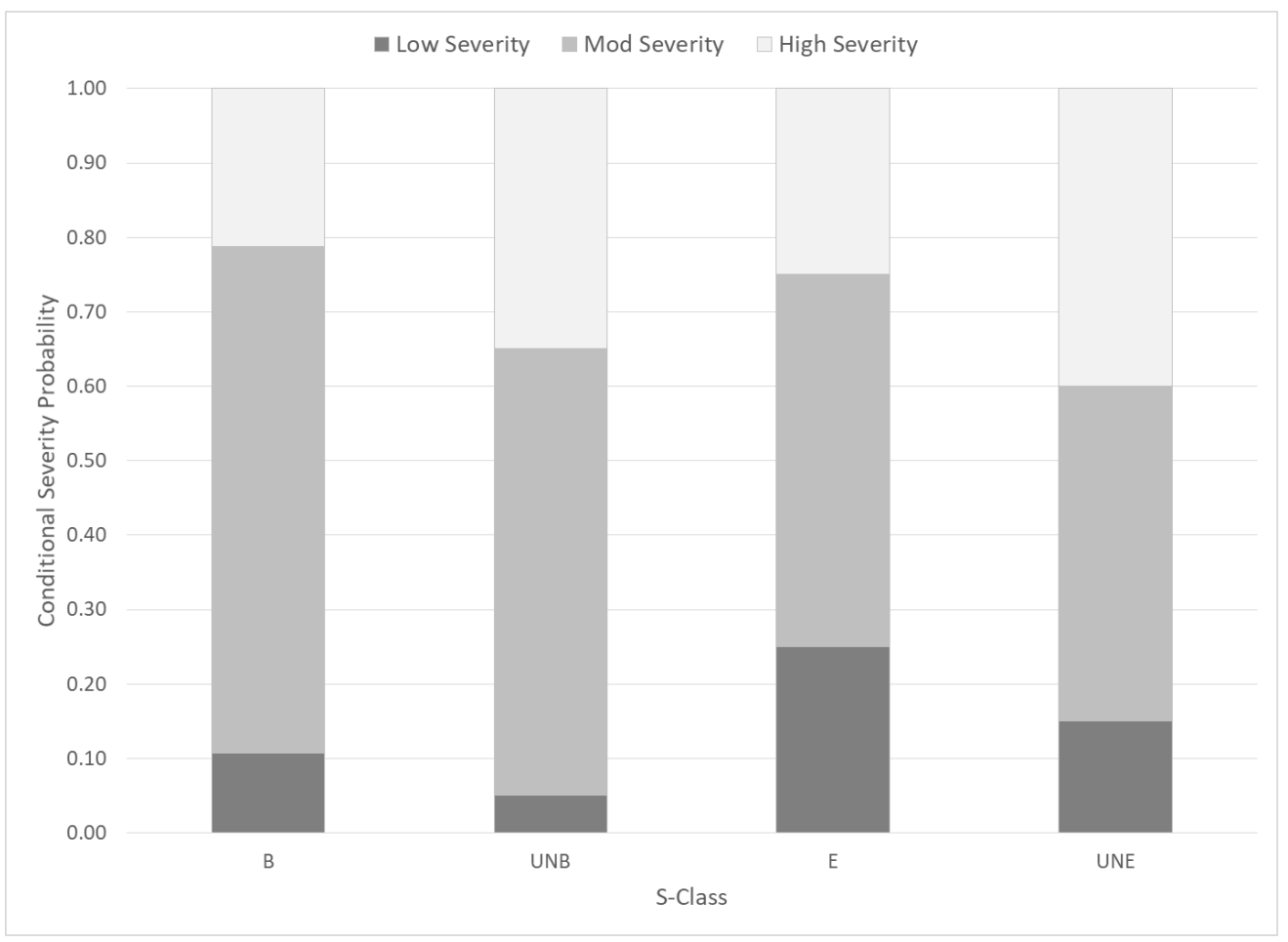

Figure A2. Conditional burn severity probability distributions for S-Classes B, UNB, E, and UNE.

A readily evident pattern in Figures A3 and A4 is the divergence of the Baseline model from the models with uncharacteristic flows and stocks (UNF/UNS). In Figure A3, the Baseline model shows a very weak increase in high-severity fire as the burn rate decreases. The addition of UN stocks and flows have a stronger effect on increasing the percentage of area burned at high severity, with a steep nonlinear increase in burn severity as burn rate decreases. This effect is more pronounced with the addition of UN stocks on top of UN flows, and with the fuel accumulation (fa) parameter set to 2 . The UNF-fa-2 line is higher than the UNS-fa-1, suggesting that the rate of recruitment into denser forest S-Classes may be as important as the rate at which those S-Classes burn with high severity (UN stocks burn with higher severity). Not surprisingly, the UNS-fa-2 model generates the highest burn severity, reaching approximately $17 \%$ when the burn rate drops to 0.01 (100-year MFRI).

In Figure A4, the Baseline model shows increasing area of D as the burn rate decreases, whereas models with UN stocks and flows show the opposite trend. As with Figure A4, the difference from the Baseline model increases with the addition of UN stocks and with the increment of the fuel accumulation parameter. In the extreme cases, when the burn rate decreases from 0.1 to 0.01 , the Baseline model increases the stock of D by $17.68 \%$, and decreases and the UNS-fa- 2 decreases the stock of D by $49.24 \%$.

The underlying explanation for these stark differences is that the Baseline model fails to account for the role of fire exclusion in driving accumulation of uncharacteristic (UN) fuel loads. As a result, the Baseline model doesn't capture the increased rates of high burn severity associated with denser forest conditions (Figure A3), nor does it capture the associated depletion of S-Class D due to recruitment into denser stocks (Figure A4). These findings are not surprising given the Baseline model was only intended to simulate a natural fire regime, and confirm our expectations that the unadjusted Baseline model would be ill-suited for simulation of contemporary human-dominated fire exclusion regimes or of alternative fire management policies. We therefore opted to use the UNS-fa-2 model for all future policy and scenario analysis, because it shows the greatest potential for high-severity fire and the highest departure of forest conditions (deficit of D) that are generally reflective of current conditions. In future work we plan to model specific landscape locations and adjust parameterization to reflect local on-the-ground conditions. 


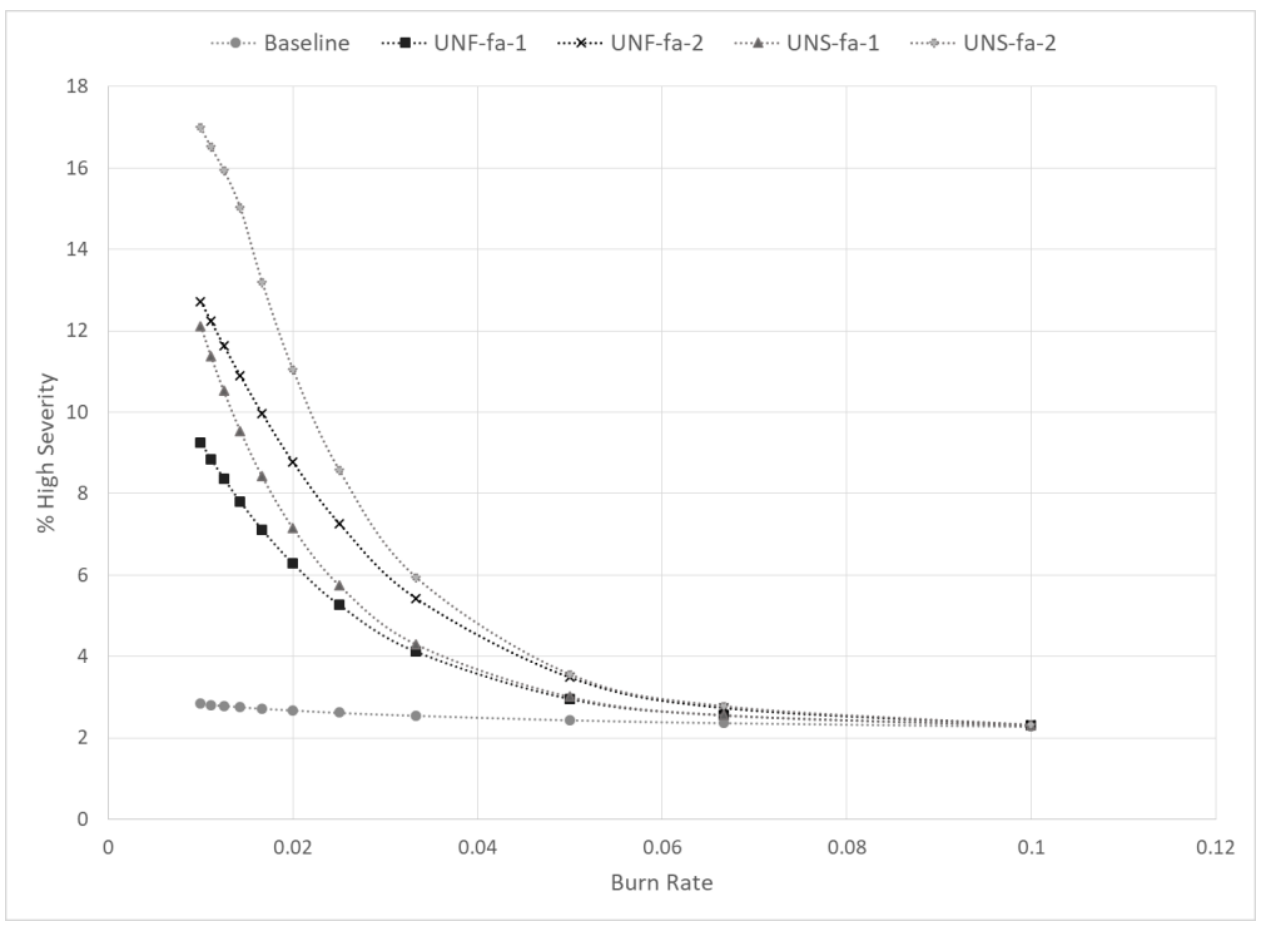

Figure A3. Steady state analysis illustrating influence of burn rate on high-severity fire percentage, across five modeling formulations.

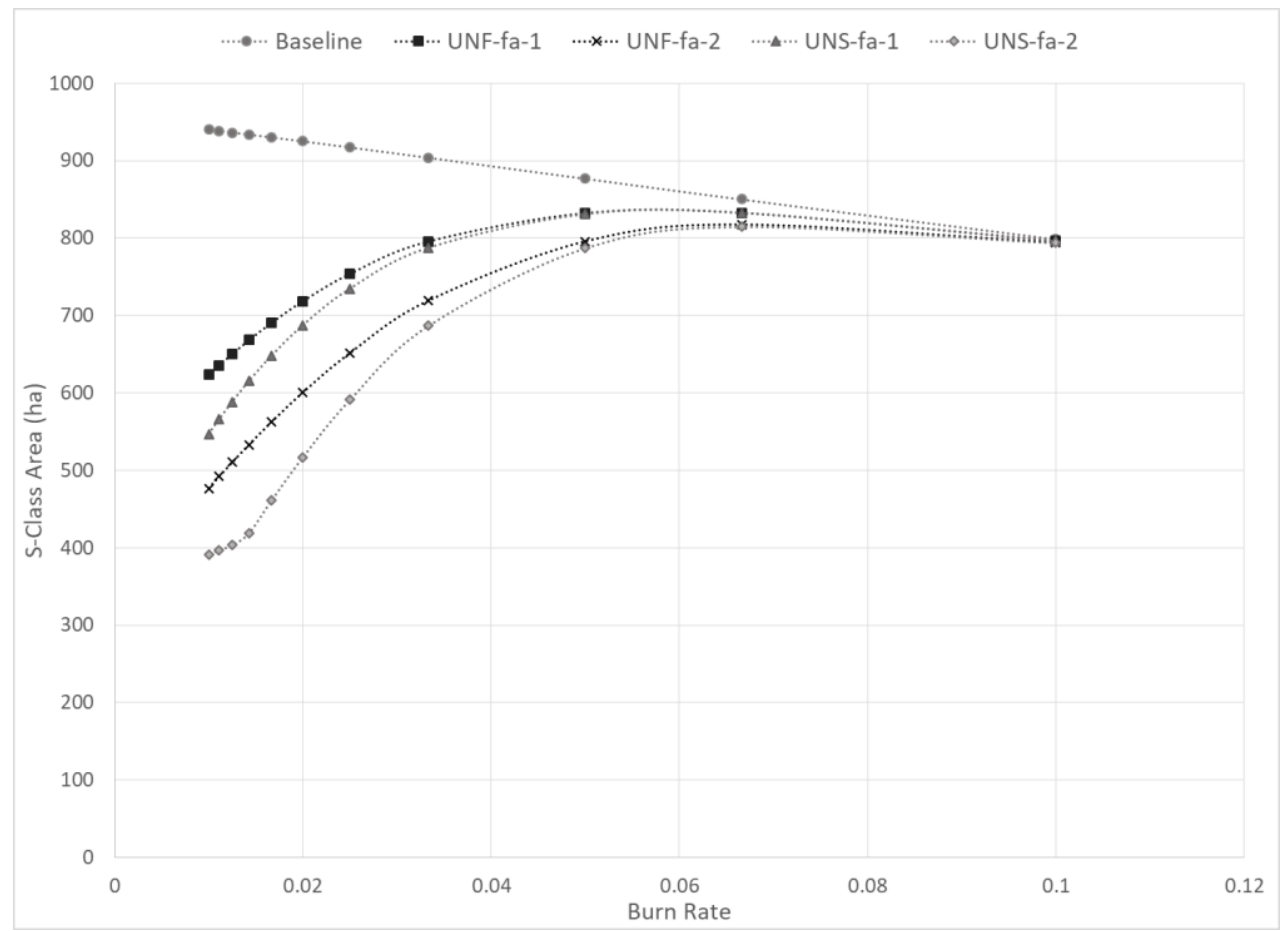

Figure A4. Steady state analysis illustrating influence of burn rate on area of S-Class D, across five modeling formulations.

\section{References}

1. Steelman, T.; Nowell, B. Evidence of effectiveness in the Cohesive Strategy: Measuring and improving wildfire response. Int. J. Wildland Fire 2019, 28, 267-274. [CrossRef] 
2. Thompson, M.P.; Dunn, C.J.; Calkin, D.E. Systems thinking and wildland fire management. In Proceedings of the 60th Annual Meeting of the ISSS-2016, Boulder, CO, USA, 23-30 July 2016; Volume 1. No. 1.

3. Thompson, M.P.; MacGregor, D.G.; Dunn, C.J.; Calkin, D.E.; Phipps, J. Rethinking the wildland fire management system. J. For. 2018, 116, 382-390. [CrossRef]

4. Spies, T.A.; Hammer, R.; White, E.M.; Kline, J.D.; Bailey, J.; Bolte, J.; Platt, E.; Olsen, C.S.; Jacobs, D.; Shindler, B. Examining fire-prone forest landscapes as coupled human and natural systems. Ecol. Soc. 2014, 19, 9. [CrossRef]

5. Calkin, D.E.; Thompson, M.P.; Finney, M.A. Negative consequences of positive feedbacks in US wildfire management. For. Ecosyst. 2015, 2, 9. [CrossRef]

6. North, M.P.; Stephens, S.L.; Collins, B.M.; Agee, J.K.; Aplet, G.; Franklin, J.F.; Fule, P.Z. Reform forest fire management. Science 2015, 349, 1280-1281. [CrossRef]

7. Parks, S.A.; Holsinger, L.M.; Miller, C.; Nelson, C.R. Wildland fire as a self-regulating mechanism: The role of previous burns and weather in limiting fire progression. Ecol. Appl. 2015, 25, 1478-1492. [CrossRef]

8. Regos, A.; Aquilué, N.; Retana, J.; De Cáceres, M.; Brotons, L. Using unplanned fires to help suppressing future large fires in Mediterranean forests. PLoS ONE 2014, 9, e94906. [CrossRef]

9. Thompson, M.P.; Freeborn, P.; Rieck, J.D.; Calkin, D.E.; Gilbertson-Day, J.W.; Cochrane, M.A.; Hand, M.S. Quantifying the influence of previously burned areas on suppression effectiveness and avoided exposure: A case study of the Las Conchas Fire. Int. J. Wildland Fire 2016, 25, 167-181. [CrossRef]

10. North, M.; Brough, A.; Long, J.; Collins, B.; Bowden, P.; Yasuda, D.; Miller, J.; Sugihara, N. Constraints on mechanized treatment significantly limit mechanical fuels reduction extent in the Sierra Nevada. J. For. 2014, 113, 40-48. [CrossRef]

11. Barnett, K.; Parks, S.; Miller, C.; Naughton, H. Beyond fuel treatment effectiveness: Characterizing Interactions between fire and treatments in the US. Forests 2016, 7, 237. [CrossRef]

12. Vaillant, N.M.; Reinhardt, E.D. An evaluation of the Forest Service Hazardous Fuels Treatment Program-Are we treating enough to promote resiliency or reduce hazard? J. For. 2017, 115, 300-308. [CrossRef]

13. Schultz, C.; Huber-Stearns, H.; McCaffrey, S.; Quirke, D.; Ricco, G.; Moseley, C. Prescribed Fire Policy Barriers and Opportunities: A Diversity of Challenges and Strategies Across the West; Ecosystem Workforce Program Institute for a Sustainable Environment, University of Oregon: Eugene, OR, USA, 2018. Available online: https://ewp.uoregon.edu/sites/ewp.uoregon.edu/files/WP_86.pdf (accessed on 10 July 2019).

14. North, M.; Collins, B.M.; Stephens, S. Using fire to increase the scale, benefits, and future maintenance of fuels treatments. J. For. 2012, 110, 392-401. [CrossRef]

15. Collins, B.M.; Lydersen, J.M.; Fry, D.L.; Wilkin, K.; Moody, T.; Stephens, S.L. Variability in vegetation and surface fuels across mixed-conifer-dominated landscapes with over 40 years of natural fire. For. Ecol. Manag. 2016, 381, 74-83. [CrossRef]

16. Boisramé, G.F.; Thompson, S.E.; Kelly, M.; Cavalli, J.; Wilkin, K.M.; Stephens, S.L. Vegetation change during 40 years of repeated managed wildfires in the Sierra Nevada, California. For. Ecol. Manag. 2017, 402, 241-252.

17. Boisramé, G.; Thompson, S.; Collins, B.; Stephens, S. Managed wildfire effects on forest resilience and water in the Sierra Nevada. Ecosystems 2017, 20,717-732.

18. Haugo, R.D.; Kellogg, B.S.; Cansler, C.A.; Kolden, C.A.; Kemp, K.B.; Robertson, J.C.; Metlen, K.L.; Vaillant, N.M.; Restaino, C.M. The missing fire: Quantifying human exclusion of wildfire in Pacific Northwest forests, USA. Ecosphere 2019, 10, e02702. [CrossRef]

19. Houtman, R.M.; Montgomery, C.A.; Gagnon, A.R.; Calkin, D.E.; Dietterich, T.G.; McGregor, S.; Crowley, M. Allowing a wildfire to burn: Estimating the effect on future fire suppression costs. Int. J. Wildland Fire 2013, 22, 871-882. [CrossRef]

20. Barros, A.M.; Ager, A.A.; Day, M.A.; Krawchuk, M.A.; Spies, T.A. Wildfires managed for restoration enhance ecological resilience. Ecosphere 2018, 9, e02161. [CrossRef]

21. Taylor, M.H.; Sanchez Meador, A.J.; Kim, Y.S.; Rollins, K.; Will, H. The economics of ecological restoration and hazardous fuel reduction treatments in the ponderosa pine forest ecosystem. For. Sci. 2015, 61, 988-1008. [CrossRef]

22. Keane, R.E.; Gray, K.; Davis, B.; Holsinger, L.M.; Loehman, R. Evaluating ecological resilience across wildfire suppression levels under climate and fuel treatment scenarios using landscape simulation modelling. Int. J. Wildland Fire 2019, 28, 533-549. [CrossRef]

23. Riley, K.; Thompson, M.; Scott, J.; Gilbertson-Day, J. A model-based framework to evaluate alternative wildfire suppression strategies. Resources 2018, 7, 4. [CrossRef] 
24. Collins, R.D.; de Neufville, R.; Claro, J.; Oliveira, T.; Pacheco, A.P. Forest fire management to avoid unintended consequences: A case study of Portugal using system dynamics. J. Environ. Manag. 2013, 130, 1-9. [CrossRef] [PubMed]

25. O'Connor, C.; Thompson, M.; Rodríguez y Silva, F. Getting ahead of the wildfire problem: Quantifying and mapping management challenges and opportunities. Geosciences 2016, 6, 35. [CrossRef]

26. O'Connor, C.D.; Calkin, D.E.; Thompson, M.P. An empirical machine learning method for predicting potential fire control locations for pre-fire planning and operational fire management. Int. J. Wildland Fire 2017, 26, 587-597.

27. Wei, Y.; Thompson, M.P.; Scott, J.H.; O'Connor, C.D.; Dunn, C.J. Designing Operationally Relevant Daily Large Fire Containment Strategies Using Risk Assessment Results. Forests 2019, 10, 311. [CrossRef]

28. Ingalsbee, $\mathrm{T}$. Whither the paradigm shift? Large wildland fires and the wildfire paradox offer opportunities for a new paradigm of ecological fire management. Int. J. Wildland Fire 2017, 26, 557-561. [CrossRef]

29. DeMeo, T.; Haugo, R.; Ringo, C.; Kertis, J.; Acker, S.; Simpson, M.; Stern, M. Expanding Our Understanding of Forest Structural Restoration Needs in the Pacific Northwest. Northwest Sci. 2018, 92, 18-36. [CrossRef]

30. Scott, J.H.; Helmbrecht, D.J.; Thompson, M.P. Assessing the Expected Effects of Wildfire on Vegetation Condition on the Bridger-Teton National Forest, Wyoming, USA; Res. Note: RMRS-RN-7; US Department of Agriculture, Forest Service, Rocky Mountain Research Station: Fort Collins, CO, USA, 2014; Volume 71, p. 36.

31. Minas, J.P.; Hearne, J.W.; Handmer, J.W. A review of operations research methods applicable to wildfire management. Int. J. Wildland Fire 2012, 21, 189-196. [CrossRef]

32. Martell, D.L. A review of recent forest and wildland fire management decision support systems research. Curr. For. Rep. 2015, 1, 128-137. [CrossRef]

33. Littell, J.S.; McKenzie, D.; Peterson, D.L.; Westerling, A.L. Climate and wildfire area burned in western US ecoprovinces, 1916-2003. Ecol. Appl. 2009, 19, 1003-1021. [CrossRef]

34. Parks, S.; Dobrowski, S.; Panunto, M. What Drives Low-Severity Fire in the Southwestern USA? Forests 2018, 9, 165. [CrossRef]

35. O'Connor, C.D.; Falk, D.A.; Lynch, A.M.; Swetnam, T.W.; Wilcox, C.P. Disturbance and productivity interactions mediate stability of forest composition and structure. Ecol. Appl. 2017, 27, 900-915. [CrossRef] [PubMed]

36. Barros, A.M.; Ager, A.A.; Day, M.A.; Palaiologou, P. Improving long-term fuel treatment effectiveness in the National Forest System through quantitative prioritization. For. Ecol. Manag. 2019, 433, 514-527. [CrossRef]

37. Finney, M.A.; Seli, R.C.; McHugh, C.W.; Ager, A.A.; Bahro, B.; Agee, J.K. Simulation of long-term landscape-level fuel treatment effects on large wildfires. Int. J. Wildland Fire 2008, 16, 712-727. [CrossRef]

38. Scott, J.H.; Thompson, M.P.; Gilbertson-Day, J.W. Examining alternative fuel management strategies and the relative contribution of National Forest System land to wildfire risk to adjacent homes-A pilot assessment on the Sierra National Forest, California, USA. For. Ecol. Manag. 2016, 362, 29-37. [CrossRef]

39. Gannon, B.M.; Wei, Y.; MacDonald, L.H.; Kampf, S.K.; Jones, K.W.; Cannon, J.B.; Wolk, B.H.; Cheng, A.S.; Addington, R.N.; Thompson, M.P. Prioritising fuels reduction for water supply protection. Int. J. Wildland Fire 2019. [CrossRef]

40. Fire Executive Council. Guidance for Implementation of Federal Wildland Fire Management Policy. 2009. Available online: https://www.nifc.gov/policies/policies_documents/GIFWFMP.pdf (accessed on 22 July 2019).

41. National Interagency Fire Center. Interagency Standards for Fire and Fire Aviation Operations 2019. 2019. Available online: https://www.nifc.gov/policies/pol_ref_redbook.html (accessed on 22 July 2019).

42. Thompson, M.; Bowden, P.; Brough, A.; Scott, J.; Gilbertson-Day, J.; Taylor, A.; Anderson, J.; Haas, J. Application of wildfire risk assessment results to wildfire response planning in the southern Sierra Nevada, California, USA. Forests 2016, 7, 64. [CrossRef]

43. O'Connor, C.D.; Calkin, D.E. Engaging the fire before it starts: A case study from the 2017 Pinal Fire (Arizona). Wildfire 2019, 28, 14-18.

44. Dunn, C.J.; Thompson, M.P.; Calkin, D.E. A framework for developing safe and effective large-fire response in a new fire management paradigm. For. Ecol. Manag. 2017, 404, 184-196. [CrossRef]

45. Meadows, D. Thinking in Systems: A Primer; Chelsea Green Publishing: White River Junction, VT, USA, 2008.

46. Fischer, A.P.; Spies, T.A.; Steelman, T.A.; Moseley, C.; Johnson, B.R.; Bailey, J.D.; Ager, A.A.; Bourgeron, P.; Charnley, S.; Collins, B.M.; et al. Wildfire risk as a socioecological pathology. Front. Ecol. Environ. 2016, 14, 276-284. [CrossRef] 
47. Hamilton, M.; Fischer, A.P.; Ager, A. A social-ecological network approach for understanding wildfire risk governance. Glob. Environ. Chang. 2019, 54, 113-123. [CrossRef]

48. Paveglio, T.B.; Moseley, C.; Carroll, M.S.; Williams, D.R.; Davis, E.J.; Fischer, A.P. Categorizing the social context of the wildland urban interface: Adaptive capacity for wildfire and community "archetypes". For. Sci. 2014, 61, 298-310. [CrossRef]

49. Rollins, M.G. LANDFIRE: A nationally consistent vegetation, wildland fire, and fuel assessment. Int. J. Wildland Fire 2009, 18, 235-249. [CrossRef]

50. Ryan, K.C.; Opperman, T.S. LANDFIRE-A national vegetation/fuels data base for use in fuels treatment, restoration, and suppression planning. For. Ecol. Manag. 2013, 294, 208-216. [CrossRef]

51. Tedim, F.; Leone, V.; Amraoui, M.; Bouillon, C.; Coughlan, M.; Delogu, G.; Fernandes, P.; Ferreira, C.; McCaffrey, S.; McGee, T.; et al. Defining extreme wildfire events: Difficulties, challenges, and impacts. Fire 2018, 1, 9. [CrossRef]

52. Stevens, J.T.; Collins, B.M.; Miller, J.D.; North, M.P.; Stephens, S.L. Changing spatial patterns of stand-replacing fire in California conifer forests. For. Ecol. Manag. 2017, 406, 28-36. [CrossRef]

53. Page, W.G.; Alexander, M.E.; Jenkins, M.J. Wildfire's resistance to control in mountain pine beetle-attacked lodgepole pine forests. For. Chron. 2013, 89, 783-794. [CrossRef]

54. Dunn, C.J.; O'Connor, C.D.; Reilly, M.J.; Calkin, D.E.; Thompson, M.P. Spatial and temporal assessment of responder exposure to snag hazards in post-fire environments. For. Ecol. Manag. 2019, 441, 202-214. [CrossRef]

55. Daniel, C.J.; Frid, L.; Sleeter, B.M.; Fortin, M.J. State-and-transition simulation models: A framework for forecasting landscape change. Methods Ecol. Evol. 2016, 7, 1413-1423. [CrossRef]

56. Hart, S.J.; Henkelman, J.; McLoughlin, P.D.; Nielsen, S.E.; Truchon-Savard, A.; Johnstone, J.F. Examining forest resilience to changing fire frequency in a fire-prone region of boreal forest. Glob. Chang. Biol. 2019, 25, 869-884. [CrossRef]

57. Wei, Y.; Thompson, M.P.; Haas, J.R.; Dillon, G.K.; O'Connor, C.D. Spatial optimization of operationally relevant large fire confine and point protection strategies: Model development and test cases. Can. J. For. Res. 2018, 48, 480-493. [CrossRef]

58. Stevens-Rumann, C.S.; Kemp, K.B.; Higuera, P.E.; Harvey, B.J.; Rother, M.T.; Donato, D.C.; Morgan, P.; Veblen, T.T. Evidence for declining forest resilience to wildfires under climate change. Ecol. Lett. 2018, 21, 243-252. [CrossRef] [PubMed] 